In: S. Paule (szerk.), Polymers and Polymeric Composites: A Reference Series, SpringerVerlag Berlin, Heidelberg, pp. 1-43 (2016) http://link.springer.com/referenceworkentry/10.1007/978-3-642-37179-0_7-1 DOI:10.1007/978-3-642-37179-0_7-1

\title{
Particulate Fillers in Thermoplastics
}

\author{
János Móczó ${ }^{1,2}$, Béla Pukánszky ${ }^{1,2, \dagger}$ \\ ${ }^{1}$ Laboratory of Plastics and Rubber Technology, Department of Physical Chemistry and \\ Materials Science, Budapest University of Technology and Economics, H-1521 Budapest, \\ P.O. Box 91, Hungary \\ ${ }^{2}$ Institute of Materials and Environmental Chemistry, Chemical Research Centre, \\ Hungarian Academy of Sciences, H-1525 Budapest, P.O. Box 17, Hungary
}

\section{Keywords}

Particulate filled polymers; Interfacial interactions; Surface modification; Deformation and failure; Composition dependence of properties;

\section{Definition}

The characteristics of particulate filled thermoplastics are determined by four factors: component properties, composition, structure and interfacial interactions. The most important filler characteristics are particle size, size distribution, specific surface area and particle shape, while the main matrix property is stiffness. Segregation, aggregation and the orientation of anisotropic particles determine structure. Interfacial interactions lead to the formation of a stiff interphase considerably influencing properties. Interactions are changed by surface modification, which must be always system specific and selected according to its 
goal. Under the effect of external load inhomogeneous stress distribution develops around heterogeneities, which initiate local micromechanical deformation processes determining the macroscopic properties of the composites.

\section{INTRODUCTUION}

Particulate filled polymers are used in very large quantities in all kinds of applications. The total consumption of fillers in Europe alone is currently estimated as 4.8 million tons (Table 1) [6]. In spite of the overwhelming interest in nanocomposites, biomaterials and natural fiber reinforced composites, considerable research and development is done on particulate filled polymers even today. The reason for the continuing interest in traditional composites lays, among others, in the changed role of particulate fillers. In the early days fillers were added to the polymer to decrease price. However, the ever increasing technical and aesthetical requirements as well as soaring material and compounding costs require the utilization of all possible advantages of fillers. Fillers increase stiffness and heat deflection temperature, decrease shrinkage and improve the appearance of the composites [9-13]. Productivity can be also increased in most thermoplastic processing technologies due to their decreased specific heat and increased heat conductivity $[9,10,14-17]$. Fillers are very often introduced into the polymer to create new functional properties not possessed by the matrix polymer at all like flame retardancy or conductivity [18-21]. Another reason for the considerable research activity is that new fillers and reinforcements emerge continuously among others layered silicates [7,22-29], wood flour [30-37], sepiolite [38-49], etc.

The properties of all heterogeneous polymer systems are determined by the same four factors: component properties, composition, structure and interfacial interactions $[9$, 50]. Although certain fillers and reinforcements including layered silicates, other nanofillers, or natural fibers possess special characteristics, the effect of these four factors is universal and valid for all particulate filled materials. As a consequence, in this paper 
we focus our attention on them and discuss the most important theoretical and practical aspects of composite preparation and use accordingly. The general rules of heterogeneous materials apply also for nano- and wood reinforced composites.

\section{FACTORS}

All four factors mentioned in the previous section are equally important in the determination of composite properties and they must be adjusted to achieve optimum performance and economics.

Component properties. The characteristics of the matrix strongly influence the effect of the filler on composite properties; reinforcing effect increases with decreasing matrix stiffness. True reinforcement takes place in elastomers, both stiffness and strength increases [51]. This effect is demonstrated well by Fig. 1, in which the tensile yield stress of $\mathrm{CaCO}_{3}$ composites is plotted against composition for two different matrices. LDPE is reinforced by the filler, while the yield stress of PVC containing the same filler decreases continuously with increasing filler content [52]. For the sake of easier comparison the data were plotted on a relative scale, related to the yield stress of the matrix. The direction of the change in yield stress or strength is determined by the relative load bearing capacity of the components $[53,54]$. In weak matrices the filler carries a significant part of the load, it reinforces the polymer.

Composition. Composition, i.e. the filler content of composites may change in a wide range. The effect of changing composition on composite properties is clearly seen in Fig. 1. The interrelation of various factors determining composite properties is also demonstrated by the figure, the same property may change in a different direction as a function of matrix characteristics, or interfacial adhesion. The goal of the use of fillers is either to decrease cost or to improve properties, e.g. stiffness, dimensional stability, etc. These goals require the introduction of the largest possible amount of filler into the polymer, but the improvement of the targeted property may be accompanied by the 
deterioration of others. Since various properties depend in a different way on filler content, composite properties must be always determined as a function of composition.

Structure. The structure of particulate filled polymers seems to be simple, the homogeneous distribution of particles in the polymer matrix is assumed in most cases. This, however rarely occurs and often special, particle related structures develop in the composites. The most important of these are aggregation and the orientation of anisotropic filler particles.

Interfacial interactions. Particle/particle interactions induce aggregation, while matrix/filler interactions lead to the development of an interphase with properties different from those of both components. Secondary, van der Waals forces play a crucial role in the development of both kinds of interactions. They are usually modified by the surface treatment of the filler. Reactive treatment, i.e. coupling, is also used occasionally, although its importance is smaller in thermoplastics than in thermoset matrices.

\section{FILLER CHARACTERISTICS}

The chemical composition of fillers, which is usually supplied by the producer as relevant information, is not sufficient for their characterization [9,57], further physical, mostly particle characteristics are needed to forecast their performance in a composite for any application [9]. A large variety of materials are used as fillers in composites. Besides $\mathrm{CaCO}_{3}$ and carbon black (see Table 1) a large number of other materials like mica $[63,73,95]$, short [96-98] and long glass fibers [99,100], glass beads [101-110], sepiolite [38-49], magnesium and aluminum hydroxide [111-113], wood flour and cellulose [3037,115-117], wollastonite [102,118-120], gypsum [121,122], clay [63], metal powders (aluminum, iron, nickel) [89,123], steel fibers [124], silicium carbide [123], phenolic microspheres [74] and diverse flame retardants [75] are also mentioned as potential fillers or reinforcements. 


\subsection{Particle size and distribution}

The mechanical properties of polymer composites containing uncoated fillers are determined mainly by their particle characteristics. One of the basic information supplied by the manufacturer is average particle size. Particle size has a pronounced influence on composite properties $[9,59,126,127]$. Modulus, sometimes strength increase, deformability and impact resistance usually decrease with decreasing particle size. Particle size itself, however, is not sufficient for the characterization of any filler; the knowledge of the particle size distribution is equally important [9]. Large particles usually deteriorate the deformation and failure characteristics of composites. Large particles easily debond from the matrix under loading often leading to the premature failure of the part. Debonding stress decreases with increasing particle size [101,128]. The other end of the particle size distribution, i.e. the amount of small particles, is equally important. The aggregation tendency of fillers increases with decreasing particle size [94,129,130]. Extensive aggregation leads to insufficient homogeneity, rigidity and low impact strength as aggregated filler particles act as crack initiation sites [63,94,132-134].

The particle size distribution of fillers is usually determined in dispersion by light scattering. This, however, can be very misleading. The particle size distribution of two fillers is presented in Fig. 2. Both fillers have a tendency for aggregation, since they contain a fraction of small particles, and the particle size distributions determined by sedimentation and microscopy differ significantly from each other. These differences appear also in the properties of the composites.

\subsection{Specific surface area, surface energy}

The specific surface area of fillers is closely related to their particle size distribution and it has a direct impact on composite properties. The adsorption of small 
molecular weight additives, but also that of the polymer is proportional to the area of the matrix/filler interface $[9,57]$. The adsorption of additives may change stability, while matrix/filler interaction significantly influences mechanical properties, first of all yield stress, tensile strength and impact resistance [53,54].

The surface free energy of fillers determines both matrix/filler and particle/particle interactions. The former has a pronounced effect on the mechanical properties of the composite; the latter determines aggregation $[9,135]$. Both interactions can be modified by surface treatment. Non-reactive treatment leads to improved dispersion, but to decreased matrix/filler interaction [130,135], while chemical or physical coupling results in improved strength $[136,137]$. Some fillers and reinforcements are supplied with surface coating. The amount and character of the coating must be known for the successful application of the filler.

\subsection{Particle shape}

The shape of the particles influences the reinforcing effect of the filler, which increases with the anisotropy of the particle. Fillers and reinforcements are very often differentiated by their degree of anisotropy (aspect ratio). Fillers with plate-like geometry like talc, mica, or layered silicates reinforce polymers more than spherical fillers and the influence of glass fibers is expected to be even stronger (see Fig. 3) [9,57,102]. However, based on published papers, it is difficult to obtain a clear picture about the effect of particle characteristics on composite properties for anisotropic fillers. Modulus seems to increase with aspect ratio [63,138], although Parrinello [139] found the stiffness of short glass fiber filled PP to be independent both of the length and the diameter of the fibers. According to Riley [63] impact resistance increases with decreasing particle size, since large particles act as flaws, while large aspect ratio is claimed to result in increased stress concentration. Tensile strength is said to decrease with increasing particle size, although 
Trotignon [140] did not observe any change in strength as a function of this characteristic. In spite of these contradictions, or just because of them, it is clear that the aspect ratio and its distribution also must be considered in the application of anisotropic fillers. Anisotropic fillers orientate during processing and they reinforce the polymer only if their orientation is parallel to the direction of the load. Since orientation is often not determined, the real effect of aspect ratio or particle characteristics in general is difficult to judge.

\subsection{Other characteristics}

The chemical composition and especially purity of fillers have both direct and indirect effect on their application possibilities and performance. Traces of heavy metal contamination decrease the stability of polyolefins [9] and lead to the discoloration of the product. Fillers are surface coated in most applications; coupling agents must be chosen according to the chemical characteristics of both the filler and the polymer matrix. The hardness of the filler has a strong effect on the wear of the processing equipment $[9,12]$, but the size and shape of the particles, composition, viscosity, the rate of processing also influence wear [9]. The thermal properties of fillers usually have beneficiary effect on productivity and processing. Decreased heat capacity and increased heat conductivity decrease cooling time [9]. Changing overall thermal properties result in the modification of the skin/core morphology of crystalline polymers and the properties of injection molded parts. On the other hand, large differences in the thermal properties of the components may lead to the development of thermal stresses [142,143], which might be detrimental to properties.

Fillers are frequently added to polymers to achieve functional properties not possessed by the matrix polymer itself, like flame retardancy and conductivity $[17,18,75,111,112]$. The particle characteristics and physical properties of these additives have the same influence on the properties of composites as those of simple fillers. The 
characteristics of these modifiers must be optimized in order to achieve the desired goal, i.e. to produce composites with a given functional property, but acceptable mechanical characteristics and aesthetics at the same time.

\section{STRUCTURE}

Although the structure of particulate filled polymers is usually thought to be very simple, often structure related phenomena determine their properties. Structure is strongly influenced by the particle characteristics of the filler, composition and the processing technology used. The most important structure related phenomena are homogeneity, the attrition of the filler or reinforcement, aggregation, and the orientation of anisotropic particles. Occasionally fillers might modify the structure of crystalline polymers as well. All structure related effects must be controlled in order to prepare products of high quality.

\subsection{Crystalline matrices, nucleation}

The properties of crystalline polymers are determined by the relative amount of the amorphous and crystalline phases, crystal modification, the size and perfection of crystallites, the dimensions of spherulites, and by the number of tie molecules [60]. The most important effect of particulate fillers is their ability to act as nucleating agents. The very strong nucleating effect of talc in PP was proved many times $[64,65]$. Similarly to talc, layered silicates, and especially montmorillonite (MMT), were shown to nucleate polypropylene quite strongly [66-70]. The influence of other fillers and reinforcements is not so clear. Many fillers have shown weak nucleation effect in PP [71-73], while some others none $[74,75]$. A closer scrutiny of literature information and experimental data indicate that mostly physical and especially topological factors determine the nucleation effect of fillers. Fillers may influence also the crystal modification of the matrix. Introduction of talc into the $\beta$ modification of $\mathrm{PP}$ resulted in a complete change of crystalline structure, the higher crystallization temperature of the $\alpha$ modification prevented 
the formation of the $\beta$ form $[76,78,79]$. Similarly, in the presence of montmorillonite polyamide was shown to crystallize mainly in the $\gamma$ form [80-86] irrespectively of the presence and/or type of organophilization [87].

Occasionally strong correlation is claimed between the crystalline structure of the matrix and composite properties. Hutley and Darlington [91,92] found a more or less linear correlation between the crystallization temperature and the falling weight impact strength of particulate filled PP, while Maiti [90] observed an even better, linear correlation between the crystallinity and tensile characteristics of PP filled with $\mathrm{CaCO}_{3}$ (Fig. 4). However, the similar effect of the filler on two or more composite characteristics might lead to the linear correlation between tensile yield stress and crystallinity as observed by Maiti [90] and often to erroneous conclusions. The detailed analysis of experimental results obtained on PP composites containing different fillers indicated that the effect of changes in crystalline structure may be neglected especially at large filler contents [93]. A very efficient nucleating agent may change the modulus of PP from 1.4 to 1.9 GPa [61], while the introduction of $30 \mathrm{vol} \%$ talc results in a composite with a stiffness of almost $8 \mathrm{GPa}$ [94].

\subsection{Segregation, attrition}

The segregation of a second phase during processing was observed in some heterogeneous polymer systems [144,145]. Kubát and Szalánczi [144] investigated the separation of phases during the injection molding of polyethylene and polyamide using the spiral test. The two polymers contained large glass spheres of 50-100 $\mu \mathrm{m}$ size and extremely long flow paths up to $1.6 \mathrm{~m}$. They found that considerable segregation took place along the flow path; the glass content of a composite containing $25 \mathrm{wt} \%$ filler exceeded $40 \%$ locally at the end of the mold. Segregation was observed also across the cross-section of the sample; the amount of filler was larger in the core than at the walls. 
Segregation depended on filler content and it became more pronounced with increasing size of the particles. The possible segregation of talc particles dispersed in a PP matrix was investigated under more practical conditions in injection molded specimens of $4 \mathrm{x} 10 \mathrm{x}$ $150 \mathrm{~mm}$ dimensions. No differences were detected in filler content as a function of position, the particles were homogeneously distributed in the PP matrix independently of average filler content. Under practical conditions (small particles, relatively high filler content, normal flow path) segregation is of secondary importance, the filler is usually homogeneously distributed in the matrix polymer.

Another structure related phenomenon is the change of particle dimensions during processing. The attrition of fibers, i.e. the change of fiber length and length distribution, is an intensively studied question in short fiber reinforced composites [146]. Attrition may occur also in composites filled with anisotropic particles with plate like geometry, e.g. mica and talc. The cleavage of these fillers is relatively easy and considerable delamination may take place during processing, especially in injection molding at the very high shear stresses developing [136,147]. Delamination of mica particles was shown to improve most properties, but decreasing particle size may lead to aggregation [138]. Contrary to traditional fillers, delamination or exfoliation would be very advantageous in layered silicate nanocomposites.

\subsection{Aggregation}

Aggregation is a well known phenomenon in particulate filled composites. Experience has shown that the probability of aggregation increases with decreasing particle size of the filler. The occurrence and extent of aggregation is determined by the relative magnitude of the forces which hold together the particles, on the one hand, or try to separate them, on the other. Particulate filled polymers are prepared by the melt mixing of the components, thus the major attractive and separating forces must be considered 
under these conditions.

When two bodies enter into contact they are attracted to each other. The strength of adhesion between two particles is determined by their size and surface energy $[150,151]$, i.e.

$$
F_{a}=\frac{3}{2} \pi W_{A B} R_{a}
$$

where $F_{a}$ is the adhesive force between the particles, $W_{A B}$ is the reversible work of adhesion and $R_{a}=R_{1} R_{2} /\left(R_{1}+R_{2}\right)$, an effective radius for particles of different size. In the presence of fluids, i.e. in suspensions, but also in the polymer melt during homogenization, further forces act among the particles. Depending on the extent of particle wetting, Adam and Edmondson [151] specify two attractive forces. When wetting is complete, viscous force $\left(F_{v}\right)$ acts between particles separating them from each other with a constant rate. $F_{v}$ depends on the viscosity of the fluid, on separation rate and on the initial distance of the particles. The viscous force might have some importance during the homogenization of composites. If the particles are wetted only partially by the fluid (melt), liquid bridges form and capillary forces develop among them. Four main types of electrostatic forces can hold between charged particles together: Coulomb, image charge, space charge and dipole forces [152]. The magnitude of all four is around $10^{-7}-10^{-8} \mathrm{~N}$, they are significantly smaller than other forces acting among filler particles.

The number of forces separating the particles is smaller. Repulsive forces may act between particles with the same electrostatic charge. The mixing of fluids leads to the development of shear forces, which try to separate the particles. The maximum hydrodynamic force acting on spheres in a uniform shear field can be expressed as $[151,153]$

$$
F_{h}=-6.12 \pi \eta R^{2} \gamma
$$

where $\eta$ is melt viscosity and $\gamma$ is shear rate. 
Both adhesive and hydrodynamic forces depend on the size of the particles. The estimation of the two forces by Eqs. 1 and 2 shows that below a certain particle size adhesion exceeds shear forces and the particles aggregate in the melt. Since commercial fillers have a relatively broad particle size distribution, most fillers aggregate in some extent and the exact determination of the critical particle size, or any other filler characteristic at which aggregation appears is difficult.

Since the relative magnitude of adhesive and shear forces determine the occurrence and extent of aggregation in a composite, the ratio of the two forces gives information about the possibilities to avoid or decrease it, i.e.

$$
\frac{F_{a}}{F_{h}}=k \frac{W_{A B}}{\eta \gamma R}
$$

where $k$ includes all constants of Eqs. 1 and 2. Increasing shear rate and particle size will result in decreased aggregation. Naturally both can be changed only in a limited range since excessive shear leads to degradation, while large particles easily debond from the matrix under the effect of external load leading to inferior composite properties. According to Eq. 3, smaller reversible work of adhesion also improves homogeneity. Nonreactive surface treatment invariably leads to the decrease of surface tension and $W_{A B}$ (see Section 6.1.), thus to decreased aggregation, improved processability and mechanical properties.

The presence of aggregates is practically always detrimental to the properties of composites as shown in Fig. 5. The strength of $\mathrm{PP} / \mathrm{CaCO}_{3}$ composites initially increases with increasing specific surface area of the filler, but it strongly decreases when aggregation takes place at small particle sizes. The effect is even more pronounced for impact properties, the fracture resistance of composites containing aggregated particles drastically decreases with increasing number of aggregates [63,133]. Aggregates may act as fracture initiation sites and depending on aggregate strength [94] they may break under 
the effect of external load, which results in the failure of the product. The phenomenon is demonstrated by Fig. 6 showing the initiation and propagation of a crack through an aggregate in a $\mathrm{PP} / \mathrm{CaCO}_{3}$ composite containing small particles.

\subsection{Orientation of anisotropic particles}

Another processing induced structural phenomenon is the orientation of anisotropic particles. Both the phenomenon and the resulting structure are similar in short fiber reinforced and particulate filled composites. Plate like, planar reinforcements, however, have some advantages over fibers; the orientation dependent shrinkage of particulate filled composites is significantly smaller than that of the fiber reinforced ones [9]. Orientation and orientation distribution strongly influence property distribution and the overall performance of the product [156].

The orientation distribution of fibers and anisotropic particles is determined by the flow pattern and shear forces developeding during processing [157]. Orientation is observed both in extrusion [158,159] and in injection molding, and even the relatively mild shearing conditions of compression molding may induce the orientation of filler particles [159]. In injection molded PP/talc composites parallel orientation was observed at the wall, while more random distribution in the middle of the injection molded plates. Average orientation shows significant composition dependence [159]. The average orientation of particles relative to the direction of the external load determines properties. Increasing alignment results in increased reinforcement, i.e. larger modulus, stress and impact strength [162] (see Fig. 7).

The orientation of anisotropic filler particles has an especially pronounced effect on the strength of injection molded parts containing weld lines. Fountain flow in the mold leads to the orientation of particles parallel with the melt front resulting in decreased weld line strength [164-166]. Increasing particle size and filler content result in a decrease of the weld line strength [164,167], which can be improved by changing particle 
characteristics (size, treatment, aspect ratio) [164] and mold construction [165].

\section{INTERFACIAL INTERACTIONS, INTERPHASE}

Interfacial interactions play a decisive role in the determination of the mechanical properties of particulate filled polymers, but they strongly influence other characteristics like processability or aesthetics as well.

\subsection{Type and strength of interaction}

Both the polymers used as matrices in particulate filled composites and the fillers or reinforcements have the most diverse physical and chemical structures, thus a wide variety of interactions may form between them. Two boundary cases of interactions can be distinguished: covalent bonds, which rarely form spontaneously, but can be created by special surface treatments, and zero interaction, which does not exist in reality, since at least secondary, van der Waals forces always act between the components. In practice the strength of the interaction is somewhere between the two boundary cases.

The theory of adsorption interaction is applied the most widely for the description of interaction in particulate filled or reinforced polymers [172]. The approach is based on the theory of contact wetting, in which interfacial adhesion is created by secondary forces. Accordingly, the strength of the adhesive bond is assumed to be proportional to the reversible work of adhesion $\left(W_{A B}\right)$, which is necessary to separate two phases with the creation of new surfaces. The Dupré equation relates $W_{A B}$ to the surface $\left(\gamma_{A}\right.$ and $\left.\gamma_{B}\right)$ and interfacial $\left(\gamma_{A B}\right)$ tension of the components in the following way

$$
W_{A B}=\gamma_{A}+\gamma_{B}-\gamma_{A B}
$$

Unfortunately interfacial tension cannot be measured directly; it is usually derived from thermodynamic calculations. Fowkes $[173,174]$ assumed that surface tension can be divided 
into components, which can be determined separately. The theory can be applied relatively easily for apolar interactions when only dispersion forces act between surfaces. Its generalization for polar interactions is more complicated and the geometric mean approximation gained the widest acceptance. This considers only the dispersion and a polar component of surface tension, but the latter includes all polar interactions [175]. According to the approach interfacial tension can be calculated as

$$
\gamma_{A B}=\gamma_{A}+\gamma_{B}-2\left(\gamma_{A} \gamma_{B}\right)^{1 / 2}-2\left(\gamma_{A} \gamma_{B}\right)^{1 / 2}
$$

The surface tension of two thermoplastics and three fillers are listed in Table 2. Large differences can be observed both in the dispersion, but especially in the polar component. The surface tension of the majority of polymers is in the same range as shown in Table 2, in fact between that of PP and PMMA. The examples listed in the table represent the most important particulate fillers and reinforcements used in practice, since clean glass fibers possess similar surface tensions as $\mathrm{SiO}_{2}$.

Although Eq. 5 tries to take into account the effect of the polarity of the surfaces in some extent, the role of acid-base interactions in adhesion became clear and theories describing them are more and more accepted [176]. Fowkes [177] suggested that the reversible work of adhesion should be defined as

$$
W_{A B}=W_{A B}^{d}+W_{A B}^{a b}+W_{A B}^{p}
$$

where $W_{A B}{ }^{a b}$ is the part of the reversible work of adhesion created by acid-base interactions. According to Fowkes the polar component can be neglected, i.e. $W_{A B}{ }^{p} \sim 0$, thus $W_{A B}$ can be expressed as

$$
W_{A B}=2\left(\gamma_{A}^{d} \gamma_{B}^{d}\right)^{1 / 2}+n f \Delta H^{a b}
$$

where $\Delta H^{a b}$ is the change in free enthalpy due to acid-base interactions, $n$ is the number of moles interacting with a unit surface and $f$ is a conversion factor, which takes into account the difference between free energy and free enthalpy $(f \sim 1)[177,178]$. The enthalpy of acid-base 
interaction, $\Delta H^{a b}$, necessary for the determination of the specific component of the reversible work of adhesion, can be calculated from the acid-base constants of the interacting phases by using the theory of Drago [179] or Guttman [180].

In most cases the strength of the adhesive bond is characterized acceptably by the reversible work of adhesion values calculated by the above theory. Often, especially in apolar systems, a close correlation exists between $W_{A B}$ and the macroscopic properties of the composite (Fig. 8). In spite of the imperfections of the approach, the reversible work of adhesion can be used for the characterization of matrix/filler interactions in particulate filled polymers. The quantities necessary for the calculation of $W_{A B}$ can be determined by inverse gas chromatography [181], while parameters related to interfacial adhesion can be derived from appropriate models $[53,54,182]$.

\subsection{Interphase formation}

As Table 2 shows, non-treated fillers and reinforcements have high energy surfaces. During the almost exclusively used melt mixing procedure, the forces discussed in the previous section lead to the adsorption of polymer chains onto the active sites of the filler surface. The adsorption of polymer molecules results in the development of a layer which has properties different from those of the matrix polymer [183-193]. Although the character, thickness and properties of this interlayer or interphase are much discussed topics, its existence is an accepted fact now.

The overall properties of the interphase, however, are not completely clear. Based on model calculations the formation of a soft interphase is claimed [194], while in most cases the increased stiffness of composites is explained at least partly with the presence of a stiff interphase $[53,54,101,195]$. The contradiction obviously stems from two opposing effects. The imperfection of the crystallites and decreased crystallinity of the interphase should lead to smaller modulus and strength, as well as to larger deformability [188]. Adhesion and 
hindered mobility of adsorbed polymer chains, on the other hand, decrease deformability and increase the strength of the interlayer.

The thickness of the interphase is a similarly intriguing and contradictory question. It depends on the type and strength of the interaction and values from $10 \AA$ to several microns have been reported in the literature for the most diverse systems [52,135,199-208]. Since interphase thickness is calculated or deduced indirectly from measured quantities, it depends also on the method of determination. Table 3 presents some data for different particulate filled polymers. Thermodynamic considerations and extraction experiments yield interphase thicknesses which are not influenced by the extent of deformation. In mechanical measurements, however, the material is always deformed even during the determination of modulus. The role and effect of immobilized chain ends increase with increasing deformation and the determined interphase thickness increases as well, which proves that chains are attached to the surface of the filler indeed (see Table 3).

The thickness of the interphase depends on the strength of the interaction. Interphase thicknesses derived from mechanical measurements are plotted as a function of $W_{A B}$ in Fig. 9 for $\mathrm{CaCO}_{3}$ composites prepared with four different matrices: PVC, plasticized PVC (pPVC), PP and LDPE. Acid-base interactions were also considered in the calculation of $W_{A B}$ [207]. The thickness of the interphase changes linearly with increasing adhesion. The figure proves several of the points mentioned above. The reversible work of adhesion adequately describes the strength of the interactions created mostly by secondary forces and the thickness of the interphase is closely related to the strength of interaction.

The amount of polymer bonded in the interphase depends on the thickness of the interlayer and on the size of the contact area between the filler and the polymer. Interface area is related to the specific surface area of the filler $\left(A_{f}\right)$, which is inversely proportional to particle size. Modulus shows only a very weak dependence on the specific surface area of the filler [209]. Properties measured at larger deformations, e.g. tensile yield stress or tensile 
strength, depend much stronger on $A_{f}$ than modulus [209]. Fig. 10 shows that yield stresses larger than the corresponding value of the matrix can be achieved, i.e. even spherical fillers can reinforce polymers [53,54]. If adhesion is strong, yielding should be initiated at the matrix value and no reinforcement would be possible. The reinforcing effect of spherical particles can be explained only with the presence of a hard interphase having properties somewhere between those of the polymer and the filler [53,54].

\subsection{Wetting}

The maximum performance of a composite can be achieved only if the wetting of the filler or reinforcement by the polymer is perfect [62,210,211]. The non-reactive treatment of fillers with surfactants is claimed to improve wettability due to changing polarity. The improvement in mechanical properties as an effect of coating is often falsely interpreted as the result of better wetting and interaction. However, according to Fox [212] the wetting of a high energy solid by a low surface tension fluid is always complete. This condition is completely satisfied by polymers, including apolar ones like PP or PE, and all inorganic fillers (see Table 2). If wettability is characterized by the thermodynamic quantity

$$
S_{A B}=\gamma_{A}-\gamma_{B}-\gamma_{A B}
$$

where $\gamma_{A}>\gamma_{B}$, wettability decreases on surface treatment due to the drastic decrease of the surface tension of the filler. The correlation is demonstrated by Fig. 11 where $S_{A B}$ is plotted against the surface coverage of a $\mathrm{CaCO}_{3}$ filler with stearic acid [214]. The larger is $S_{A B}$ the better is wettability and in the case of negative values definite contact angle develops (partial wetting). As a consequence, wetting becomes poorer on surface coating, but it results in weaker interactions at the same time, which lead to a considerable decrease in aggregation, to better dispersion and homogeneity, easier processing, good mechanical properties and appearance. However, wetting has also kinetic conditions, which depend on 
the viscosity of the polymer, processing technology and particle characteristics, which might not always be optimal during composite preparation. However, particle related problems (debonding, aggregation) and insufficient homogenization usually create more problems than wetting.

\section{SURFACE MODIFICATION}

The easiest way to change interfacial interactions is the surface coating of fillers. Surface modification is often regarded as a magic, which solves all problems of processing technology and product quality, but it works only if the compound used for the treatment (coupling agent, surfactant, etc.) is selected according to the characteristics of the components and the goal of the modification. Surface treatment modifies both particle/particle and matrix/filler interactions, and the properties of the composite are determined by the combined effect of the two. Besides its type, also the amount of the surfactant or coupling agent must be optimized both from the technical and the economical point of view.

\subsection{Non-reactive treatment}

The oldest and most often used modification of fillers is the coverage of their surface with a small molecular weight organic compound [58,135,181,207,214]. Usually amphoteric surfactants are used which have one or more polar groups and a long aliphatic tail. Typical example is the surface treatment of $\mathrm{CaCO}_{3}$ with stearic acid $[58,135,181,207,214-216]$. The principle of the treatment is the preferential adsorption of the surfactant onto the surface of the filler. The high energy surfaces of inorganic fillers (see Table 2) can often enter into special interactions with the polar group of the surfactant. Preferential adsorption is promoted in a large extent by the formation of ionic bonds between stearic acid and the surface of $\mathrm{CaCO}_{3}$ [217], but in other cases hydrogen or even covalent bonds may also form. Surfactants diffuse to the surface of the filler even from the polymer melt, which is a further proof for 
preferential adsorption [218].

One of the crucial questions of non-reactive treatment, which, however, is very often neglected, is the amount of surfactant to use. It depends on the type of the interaction, the surface area occupied by the coating molecule, its alignment to the surface, on the specific surface area of the filler and on some other factors. The determination of the optimum amount of surfactant is essential for efficient treatment. Insufficient amount does not achieve the desired effect, while excessive quantities lead to processing problems as well as to the deterioration of the mechanical properties and appearance of the product [217,221]. The amount of bonded surfactant can be determined by simple techniques. A dissolution method proved to be very convenient for the optimization of non-reactive surface treatment and for the characterization of the efficiency of the coating technology as well $[217,222]$. First the surface of the filler is covered with increasing amounts of surfactant, and then the nonbonded part is dissolved with a solvent. The technique is demonstrated in Fig. 12, which presents a dissolution curve showing the adsorption of stearic acid on $\mathrm{CaCO}_{3}$. Surface coating is preferably carried out with the irreversibly bonded surfactant $\left(\mathrm{c}_{100)}\right)$; at this composition the total amount of surfactant used for the treatment is bonded to the filler surface. The filler can adsorb more surfactant $\left(\mathrm{c}_{\max }\right)$, but during compounding a part of it can be removed from the surface and might deteriorate properties. The specific surface area of the filler is an important factor which must be taken into consideration during surface treatment. The irreversibly bonded surfactant depends linearly on it [217].

As a result of the treatment the surface free energy of the filler decreases drastically [135,181,214,222]. Smaller surface tension means decreased wetting (see Fig. 11), interfacial tension and reversible work of adhesion [217]. Such changes in the thermodynamic quantities result in a decrease of both particle/particle and matrix/particle interaction. One of the main goals, major reason and benefit of non-reactive surface treatment is the first effect, i.e. to change interactions between the particles of fillers and reinforcements. As an effect of non- 
reactive treatment not only particle/particle, but matrix/filler interaction decreases as well. The consequence of this change is decreased yield stress and strength as well as improved deformability [135,215]. Strong interaction, however, is not always necessary or advantageous for the preparation of composites with desired properties; the plastic deformation of the matrix is the main energy absorbing process in impact, which increases with decreasing strength of adhesion [182,223-225].

\subsection{Coupling}

Successful reactive treatment assumes that the coupling agent reacts and forms covalent bonds with both components. Silane coupling agents are successfully applied for fillers and reinforcements which have reactive $-\mathrm{OH}$ groups on their surface, e.g. glass fibers, glass flakes and beads, mica and other silica fillers [140,183,228,229]. The use of silanes with fillers like $\mathrm{CaCO}_{3}, \mathrm{Mg}(\mathrm{OH})_{2}$, wood flour, etc. were tried, but often proved to be unsuccessful [230,231]; sometimes contradictory results were obtained even with glass and other siliceous fillers [232]. Acidic groups are preferable for $\mathrm{CaCO}_{3}, \mathrm{Mg}(\mathrm{OH})_{2}, \mathrm{Al}(\mathrm{OH})_{3}$ and $\mathrm{BaSO}_{4}$. Talc cannot be treated successfully either with reactive or non-reactive agents because of its inactive surface; only broken surfaces contain a few active $-\mathrm{OH}$ groups.

The adsorption of organofunctional silanes is usually accompanied by their polycondensation. The adsorbed amount of coupling agent, the structure, properties and adhesion of the polysiloxane layer depend very much on the chemical composition of the organofunctional group of the silane. This is obvious if we compare the dissolution curve of two silanes, an aliphatic and an aminosilane, respectively, on $\mathrm{CaCO}_{3}$ (Fig. 13). The different chemical structure of the silanes leads to considerably different adsorption isotherms. The figure shows also that the simple dissolution technique can be advantageously applied for the study of reactive coupling agents as well [233].

Although the chemistry of silane modification of reactive silica fillers is well 
documented, much less is known about the interaction of silanes with polymers. Thermoplastics rarely contain reactive groups, thus they cannot react chemically with silanes. Polycondensation polymers are the most reactive and literature sources offer sufficient evidence of reactive coupling, indeed. The strength of polyamide and polycarbonate composites increases on aminosilane treatment [234-236]. Reactive treatment is the most difficult in polyolefins, since they do not contain any reactive groups. Some results indicate that polypropylene oxidizes during processing even in the presence of stabilizers and the formed acidic groups react with aminosilanes resulting in reactive coupling [237].

Considering the complexity of the chemistry involved, it is not surprising that the amount of coupling agent and surface coverage have an optimum here too, similarly to surfactants in non-reactive surface treatment. The optimization of the type and amount of coupling agent is crucial also in reactive treatment and although "proprietary" coatings might lead to some improvement in properties, they are not necessarily optimal or cost effective. The improper choice of coupling agent may result in insufficient or even deteriorating effects. In some cases hardly any change is observed in properties, or the effect can be attributed unambiguously to the decrease of surface tension due to the coverage of the filler surface by an organic substance, i.e. to non-reactive treatment [219,220].

\subsection{Functionalized polymers}

The coverage of filler surface with a polymer layer which is capable of interdiffusion with the matrix proved to be very effective both in stress transfer and in forming a thick diffuse interphase with acceptable deformability. In this treatment the filler is usually covered by a functionalized polymer, preferably with the same chemical structure as the matrix. The functionalized polymer is attached to the surface of the filler by secondary, hydrogen, ionic and sometimes by covalent bonds. The polymer layer interdiffuses with the matrix, entanglements form and strong adhesion is created. Because of their polarity, in some cases 
reactivity, maleic anhydride or acrylic acid modified polymers are often used for this purpose. The coupling agent adsorbs onto the surface of most polar fillers even from the melt. This treatment is frequently used in polyolefin composites, in which other treatments usually fail. Often very small amounts of modified polymer (1-3 wt $\%)$ are sufficient to achieve significant improvement in stress transfer [238,239]. The maximum effect of functionalized PP was found with fillers of high energy surfaces $[232,241,242]$ or with those capable for specific interactions, e.g. ionic bond with $\mathrm{CaCO}_{3}[239,243]$ or chemical reaction with wood flour, kraft lignin or cellulose [238,240]. Fig. 14 demonstrates the successful use of functionalized polymer in PP composites modified with $\mathrm{CaCO}_{3}$ and wood flour, respectively.

\subsection{Soft interlayer}

The introduction of hard particles into the polymer matrix creates stress concentration, which induces local micromechanical deformation processes. Occasionally these might be advantageous for increasing plastic deformation and impact resistance, but they usually deteriorate the properties of the composite. The encapsulation of the filler particles by an elastomer layer changes the stress distribution around the particles and modifies local deformation processes. Encapsulation can take place spontaneously, it can be promoted by the use of functionalized elastomers or the filler can be treated in advance. Such a surface modification is rarely done directly by covering the filler with a soft layer, but forms spontaneously during the preparation of multicomponent polymer/filler/elastomer composites $[\mathbf{x}]$.

\section{MICROMECHANICAL DEFORMATIONS}

The introduction of fillers or reinforcements into a polymer matrix results in a heterogeneous system. Under the effect of external load heterogeneities induce stress concentration, the magnitude of which depends on the geometry of the inclusions, the 
elastic properties of the components and interfacial adhesion [244,245]. Heterogeneous stress distribution and local stress maxima initiate local micromechanical deformations, which determine the deformation and failure behavior, as well as the overall performance of the composites. Stress concentration and local stress distribution can be estimated by the use of theoretical models or by finite element analysis [56,246,247]. The interacting stress fields of neighboring particles are very complicated and change with composition. The most often used approach is the analysis of stresses around a single particle embedded in an infinite matrix, which was first proposed by Goodier [244]. According to his model radial stress has a maximum at the pole, where it exceeds almost twice the external stress. Micromechanical deformation processes initiated by local stress maxima around the particles are influenced also by thermal stresses induced by the different thermal expansion coefficients of the components, crystallization, or shrinkage during the curing of thermoset matrices [142,143]. Although the importance of inhomogeneous stress distribution developing in particulate filled composites is pointed out in numerous publications, the exact role of stress concentration is not completely clear and contradictory information is poublished claiming either beneficial [254], neutral [255] or detrimental effect on properties [63,195].

In particulate filled polymers the dominating micromechanical deformation process is debonding. The stress necessary to initiate debonding, the number of debonded particles and the size of the voids formed all influence the macroscopic properties of composites. Several models exist for the prediction of debonding stress including the one below [56]

$$
\sigma^{D}=-C_{1} \sigma^{T}+C_{2}\left(\frac{W_{A B} E}{R}\right)^{1 / 2}
$$

where $\sigma^{D}$ and $\sigma^{T}$ are debonding and thermal stresses, respectively, $W_{A B}$ is the reversible work of adhesion and $R$ denotes the radius of the particle. $C_{1}$ and $C_{2}$ are constants which depend on the geometry of the debonding process. The validity of the model was checked 
in various particulate filled composites. Initiation stress determined in $\mathrm{PP} / \mathrm{CaCO}_{3}$ composites from volume strain measurements is plotted against the stiffness of the matrix in Fig. 15 in the representation predicted by the model [253]. The correlation is close and corresponds to the prediction. Similarly good correlations can be obtained if we plot debonding stress against the reversible work of adhesion [259] or the particle size of the filler [252] (see Eq. 9).

Micromechanical deformations are competitive processes and the dominating one depends on material properties and loading conditions. Several fiber related processes, like fiber breakage, pull out, buckling, etc. may take place in short and long fiber reinforced composites. Quite a few of these can be observed also in wood fiber reinforced polymers or layered silicate nanocomposites as well. The complexity of deformation and failure in such materials is demonstrated well by the number of processes detected in wood flour reinforced PP composites [116]. The stress vs. strain correlation of a PP composite containing 20 wt\% unmodified wood flour is presented in Fig. 16 together with the acoustic signals detected during deformation. Since the adhesion between wood and PP is poor and the particles are large, the majority of the signals is emitted by the debonding of the wood particles. The cumulative number of acoustic events vs. elongation plot clearly indicates that at least two processes occur in this composite shown by the two steps in the correlation. The application of a coupling agent, which improves interfacial adhesion between the components changes the mechanism of deformation completely, the fracture of the fibers dominate under those conditions. The analysis of a large number of results showed that at least four processes take place during the deformation of PP/wood composites. The PP matrix deforms mainly by shear yielding, debonding and fiber pull out dominates when the adhesion is poor, while mainly fiber fracture takes place in the presence of MAPP coupling agent, which create strong bond between the matrix and the wood particles. The fracture and the fibrillation of a particle are shown in Fig. 17 in order 
to support the analysis. The importance of local deformations is strongly supported by Fig. 18 in which composites strength is plotted against the initiation stress of the dominating process of a large number of PP and PLA composites reinforced with wood. It is obvious that micromechanical processes initiated by local stress maxima determine the final properties of particulate filled and reinforced composites and only the analysis of the resulting processes can help the development of stronger and better materials.

\section{PROPERTIES}

The properties of particulate filled thermoplastics depend strongly and usually nonlinearly on composition. Models are needed for the prediction of properties in order to produce composites with desired characteristics. Relatively few models exist for the prediction of the effect of filler content on properties and the majority of these are empirical equations.

\subsection{Rheological properties}

The introduction of fillers or reinforcements changes practically all properties of the polymer including its rheological characteristics. Viscosity usually increases with filler content, while melt elasticity decreases at the same time [270,271]. These changes depend very much on the particle characteristics of the filler although unambiguous correlations are not known. Matrix/filler interactions lead to the formation of an interphase and has the same effect as increasing filler content [185].

The composition dependence of rheological properties is modeled only in surprisingly few cases. Quite a few models are derived from Einstein's equation, which predicts the composition dependence of the viscosity of suspensions containing spherical particles. The original equation is valid only at infinite dilution, or at least at very small, 1$2 \%$, concentrations [272] and in real composites the equation must be modified. Usually 
additional terms and parameters are introduced into the model most often in the form of a power series [271,272]. The Mooney equation represents a more practical and useful approach which contains adjustable parameters accommodating both the effect of interaction and particle anisotropy $[272,273]$, i.e.

$$
\ln \frac{\eta}{\eta_{0}}=\frac{k_{E} \varphi_{f}}{1-\varphi_{f} / \varphi_{f}^{\max }}
$$

where $\eta$ and $\eta_{0}$ are the viscosity of the composite and the matrix, respectively, $\varphi$ the volume fraction of the filler, while $k_{E}$ is an adjustable parameter related to the shape of the particles. $\varphi_{f}^{\max }$ is the maximum amount of filler, which can be introduced into the composite, i.e. maximum packing fraction, and it is claimed to depend solely on the spatial arrangement of the particles. The study of $\mathrm{PP} / \mathrm{CaCO}_{3}$ composites proved that interfacial interactions and the formation of a stiff interface influences its value more than spatial arrangement and the maximum amount of filler which can be introduced into the polymer decreases with increasing specific surface area of the filler.

\subsection{Stiffness}

Modulus is one of the basic properties of composites and the goal of using particulate fillers is often to increase it [75,239]. Modulus is not only the most frequently measured, but also the most often modeled composite property. A large number of models exist which predict the composition dependence of stiffness or give at least some bounds for its value. The abundance of models is relatively easy to explain: modulus is determined at very low deformations thus the theory of linear viscoelasticity can be used in model equations. The large number of accessible data also helps both the development and the verification of models. Model equations developed for heterogeneous polymer systems can be classified in different ways [277-279]. Ignoring completely empirical correlations, we distinguish four groups here: 
1. Phenomenological equations which are similar to the spring and dashpot models used for the description of the viscoelastic properties of polymers $[\mathbf{X X}]$.

2. Bounds. These are usually exact mathematical solutions which do not contain any or only very limited assumptions about the structure of the composite [YY].

3. Self-consistent models. The mechanical response of a composite structure is calculated in which the dispersed particle is assumed to be embedded into the continuous phase. A well known model of this type, frequently used also for particulate filled composites, is the Kerner equation [277-279]. Although it was much criticized because of the incorrect elastic solution used [280], the model gained wide use and acceptance.

4. Semiempirical models. In spite of the effort of the self-consistent models to take into account the influence of microstructure, they very often fail to predict correctly the composition dependence of composite modulus, thus additional, adjustable parameters are introduced in order to improve their performance. The most often applied equation of this type is the Nielsen (also called Lewis-Nielsen or modified Kerner) model $[59,285]$.

$$
\begin{aligned}
& G=G_{m} \frac{1-A B \varphi_{f}}{1-B \Psi \varphi_{f}} \\
& A=\frac{7-5 v_{m}}{8-10 v_{m}} \\
& B=\frac{G_{f} / G_{m}-1}{G_{f} / G_{m}+A} \\
& \Psi=1+\left(\frac{1-\varphi_{f}^{\max }}{\varphi_{f}^{\max ^{2}}}\right) \varphi_{f}
\end{aligned}
$$

where $G, G_{m}$ and $G_{f}$ are the shear moduli of the composite, the matrix and the filler, respectively, $v_{m}$ is the Poisson's ratio of the matrix and $\varphi_{f}$ is filler content. The equation contains two structure related or adjustable parameters $(A, \Psi)$. The two parameters, 
however, are not very well defined. $A$ can be related to filler anisotropy, through the relation $A=k_{\mathrm{E}}-1$, where $k_{\mathrm{E}}$ is Einstein's coefficient, but the relation has not been thoroughly investigated and verified. $\Psi$ depends on maximum packing fraction. $\varphi_{f}^{\max }$ is related to anisotropy, but it is influenced also by the formation of an interphase which was not taken into consideration in the original treatment [59]. Its experimental determination is difficult. McGee and McCullogh proposed a different form for $\Psi$, which is supposed to be based on a more rigorous treatment [277].

In spite of these uncertainties the model is quite frequently used in all kinds of particulate filled composites for the prediction of the composition dependence of modulus. In some cases merely the existence of a good fit is established, in others conclusions are drawn from the results about the structure of the composite. However, the attention must be called here to some problems of the application of these equations or any other theoretical model. The uncertainty of input parameters might bias the results considerably. Poisson's ratios between 0.25 and 0.30 , as well as moduli between 19.5 and 50 GPa have been reported for $\mathrm{CaCO}_{3}[12,246,282]$. Such changes in component properties may lead to differences in the final prediction which exceed the standard deviation of the measurement. Maximum packing fraction influences predicted moduli especially strongly, but its value is usually not known. A certain packing of the particles may be assumed, but this approach neglects the effect of particle size distribution and interactions. At the moment the best solution is the fitting of the equation to the experimental data and the determination of $A$ and $\varphi_{f}^{\max }$. The model is very useful for the estimation of the amount of embedded filler in polymer/elastomer/filler composites [263], but otherwise its value is limited.

\subsection{Properties measured at large deformations}

The fact that modulus is determined at very low deformations simplifies both 
measurements and modeling. On the other hand, yield properties are measured at larger deformations making predictions much more difficult. The composition dependence of yield strain is described assuming that at the considerable deformations (5-10\%) of yielding only the polymer matrix deforms and the rigid filler does not. This strain magnification of the matrix increases with increasing filler content. One of the equations based on this principle was derived by Nielsen [59]. Occasionally the same approach is used for the prediction of the composition dependence of elongation-at-break $[59,195]$.

More attempts are made to predict and analyze yield stress. The most often applied correlation is attributed to Nicolais and Narkis [285], although the equation of Ishai and Cohen [286] is practically the same. Nicolais and Narkis [285] assumed that the filler decreases the effective cross-section of the matrix which carries the load during deformation. Assuming a certain arrangement of the particles they calculated this crosssection and from that the dependence of yield stress on composition, i.e.

$$
\sigma_{y}=\sigma_{y 0}\left(1-1.21 \varphi_{f}^{2 / 3}\right)
$$

where $\sigma_{y}$ and $\sigma_{y 0}$ are composite and matrix yield stress, respectively. The approach, however, results in a matrix cross-section assuming zero value at $\varphi_{f}<1$ which is naturally incorrect. The model assumes zero interaction and ignores all other factors influencing yield stress. Because of these simplifications, deviations from the prediction occur very often. As a consequence, the model is frequently modified to accommodate the effect of different arrangements of the particles [59], interactions, stress concentration [195,256], or other effects. Usually the two constants, i.e. 1.21 and $2 / 3$, are treated as adjustable parameters, but in such cases they lose their physical meaning and the entire approach becomes invalid.

Another model [54] takes into account at least some of the factors neglected by Nicolais and Narkis [285]. The model applies a different expression for the effective load- 
bearing cross-section [287] and takes into account also the influence of interfacial interactions and interphase formation

$$
\sigma_{y}=\sigma_{y 0} \frac{1-\varphi_{f}}{1+2.5 \varphi_{f}} \exp \left(B \varphi_{f}\right)
$$

where $B$ is related to the relative load-bearing capacity of the components, i.e. to interaction. A detailed analysis has shown that $B$ accounts both for changes in interfacial area and for the strength of interaction through the expression

$$
B=\left(1+A_{f} \rho_{f}\right) \ln \frac{\sigma_{y i}}{\sigma_{y 0}}
$$

where $A_{f}$ and $\rho_{f}$ are the specific surface area and density of the filler, while $\ell$ and $\sigma_{y i}$ are the thickness of the interphase and its yield stress, respectively. The correlation proved to be valid for most particulate filled systems [54,135,209]. The rearrangement of Eq. 16 eliminates the effect of changing matrix cross-section and if the natural logarithm of relative yield stress, i.e. $\sigma_{y r e l}=\sigma_{y}\left(1+2.5 \varphi_{f}\right) / \sigma_{y 0}\left(1-\varphi_{f}\right)$ is plotted against the volume fraction of the filler, straight lines should be obtained. The validity of the approach is proved by Fig. 19, in which the relative yield stress of the $\mathrm{PP} / \mathrm{CaCO}_{3}$ composites of Fig. 10 is plotted in the linear form. The change in the slope of the straight line indicates the effect of interfacial area $\left(A_{f}\right)$, which increases with decreasing particle size, i.e. with increasing amount of interphase formed (see Eq. 17). Parameter $B$ measures quantitatively changes in the strength of interactions achieved by surface modification.

The composition dependence of ultimate tensile properties, i.e. tensile strength and elongation-at-break is very similar to that of the yield characteristics. Usually both elongation and strength decrease with increasing filler content [111,288], although occasionally some reinforcement can be observed, too. However, changes in elongation with filler content make the prediction of strength difficult; the cross-section of the specimen decreases at large elongations, while the orientation of the matrix results in 
strain hardening. The modification of Eq. 16 successfully copes with these problems, i.e.

$$
\sigma_{T}=\sigma_{T 0} \lambda^{n} \frac{1-\varphi_{f}}{1+2.5 \varphi_{f}} \exp \left(B \varphi_{f}\right)
$$

where true tensile strength ( $\sigma_{T}=\sigma \lambda, \lambda=L / L_{0}$, relative elongation) accounts for the change in specimen cross-section and $\lambda^{n}$ for strain hardening. $n$ characterizes the strain hardening tendency of the polymer and can be determined from matrix properties [54]. $B$ is defined by a correlation similar to Eq. 17, but its value is naturally different from that determined from the composition dependence of yield stress.

Fracture and especially impact resistance are crucial properties of all materials used in engineering applications. Similarly to yield stress, the fracture toughness of particulate filled polymers is assumed to decrease with filler content, which is not necessarily true. Fracture and impact resistance often increases or goes through a maximum as a function of filler content both in thermoplastic and thermoset matrices [284,292]. Several micromechanical deformation processes take place during the deformation and fracture of heterogeneous polymer systems. New deformation processes initiated by heterogeneities always consume energy resulting in an increase of fracture resistance. The various deformation mechanisms consumption different amount of energy, thus the change of properties and composition dependence may also vary according to the actual processes taking place during deformation. Deformation mechanisms leading to increased plastic deformation of the matrix are the most efficient in improving fracture and impact resistance. Because of the effect of a large number of factors influencing fracture resistance and due to the increased role of micromechanical deformation processes, the modeling of this property is even more difficult than that of other composite characteristics. Nevertheless, a relatively large number of models have been published up to now [294-299], but very few of them gained wide acceptance. The semiempirical model applied for the description of the composition dependence of other mechanical properties (see Eqs. 16-18) can be extended also to fracture and impact resistance 
[182]. The model could be used successfully for a large number of composites both with thermoplastic and thermoset matrices.

\subsection{Other properties}

Particulate filled and reinforced polymers are frequently used in structural applications and the main goal of modification is often the improvement of stiffness. As a consequence, much attention is paid to the study and modeling of mechanical properties, but other characteristics of the composites are investigated much less and relatively few attempts are made to describe their composition dependence by models. Heat deflection temperature (HDT) is closely related to stiffness and changes with composition in a similar way. Cost is an important attribute of every engineering material and it usually decreases with increasing filler content. However, decreasing polymer prices and increasing compounding costs make particulate filled polymers competitive only if their technical benefits are utilized in their full extent. The introduction of fillers may change the appearance of the product (color, surface) or influence the stability of the compound. Heat capacity, heat conductivity, shrinkage, and dielectric properties can be described quantitatively by models used for the description of the composition dependence of modulus. Fillers influence the barrier properties of polymers, the permeation of gases and vapors decreases with increasing filler content. Models exist for the description of this phenomenon [300-304], which take into account the tortuosity of the diffusion path.

The inherent flammability of plastics is one of their major drawbacks and the use of flame retardants is required today in most applications, especially in construction or transportation. Traditional halogen/antimony flame retardants are very efficient, but their use will be banned in the future because of environmental and health considerations. One of the alternatives is the use of hydrated mineral fillers, like aluminium or magnesium hydroxides 
[305]. These can provide acceptable levels of frame retardancy without the formation of smoke or corrosive and toxic gases. Unfortunately, these minerals must be used in large quantities in order to achieve the necessary effect, which deteriorates other properties, like processability, strength and especially impact resistance. Appropriate surface modification must be used in order to overcome the negative effect of large filler content.

Polymers are basically insulators with surface resistivity of around $10^{14}-10^{18} \Omega \mathrm{cm}$. Applications exist which require a certain conductivity, like air ducts in mines, pipes for solvent transport, EMI shielding and some other areas. Conductivity is usually achieved by the introduction of conductive fillers. Traditionally special conductive carbon blacks or metal fillers, particles or flakes, are used in such applications, but recently intensive research is going on to use carbon nanofibers or nanotubes for this purpose [306,307]. Conductivity increases stepwise at a certain additive content, and the percolation threshold is claimed to be much smaller, around several tenth of a weight percent [306,307], for nanofillers than for traditional fillers. This claim is strongly supported by the results of Pötschke et al. [306,307] presented in Fig. 20. The percolation threshold of the special conducting carbon black is around $8 \mathrm{wt} \%$ in polycarbonate, while that of single walled nanotube is less than one percent in the same polymer, indeed. Such behavior can be described and the composition dependence of conductivity can be modeled with percolation theories [308,309].

\section{CONCLUSIONS}

Although particulate filled polymer composites are mature materials with a long history of application, their structure-property correlations are more complicated than usually assumed. The characteristics of all heterogeneous polymer systems including composites containing micro or nano fillers are determined by four factors: component properties, composition, structure and interfacial interactions. Several filler characteristics influence composite properties, but the most important ones are particle size, size distribution, specific 
surface area and particle shape. The main matrix property is stiffness. Composite properties usually depend non-linearly on composition, thus they must be always determined as a function of filler content. The structure of particulate filled polymers is often more complicated than expected, segregation, aggregation and the orientation of anisotropic particles may take place. Interfacial interactions invariably develop in composites; they lead to the formation of a stiff interphase considerably influencing properties. Interactions can be modified by surface treatment, which must be always system specific and selected according to the goal of modification. Particulate filled polymers are heterogeneous materials in which inhomogeneous stress distribution and stress concentration develop under the effect of external load. These initiate local micromechanical deformation processes, which determine the macroscopic properties of the composites. The dominating deformation mechanism is usually debonding in filled polymers. Although the number of reliable models to predict properties is relatively small, they offer valuable information about structure and interactions in particulate filled composites.

\section{REFERENCES}

1. J. Markarian, Plast. Additives Compound., 6, 26 (2004).

2. J. Markarian, Plast. Additives Compound., 5, 36 (2001).

3. G. Morieras, Ind. Minerals 6, 29 (2001).

4. W. R. Hale, K. K. Dohrer, M. R. Tant and I. D. Sand, Colloids Surfaces, Physicochem. Eng. Aspects, A187-188, 483 (2001).

5. W. R. Hale, J. McGuire, I. D. Sand and K. K. Dohrer, J. Appl. Polym. Sci., 82, $2454(2001)$.

6. R. N. Rothon, in Proc. High Performance Fillers 2007, Paper 1, Hamburg, Germany (2007).

7. M. Alexandre and P. Dubois, Mater. Sci. Eng., 28, 1 (2000). 
8. $\quad$ R. Stewart, Plast. Eng., 60, 22 (2004).

9. B. Pukánszky, in Polypropylene. Structure, Blends and Composites, J. KargerKocsis Ed., pp. 1-70, Chapman and Hall, London (1995).

10. B. Pukánszky, in Polypropylene. An A-Z reference, J. Karger-Kocsis Ed., pp. 240246, 574-580, Kluwer Academic, Dordrecht (1999).

11. G. Wypych, Handbook of fillers. ChemTec Publishing, Toronto (1999).

12. H. S. Katz and J. V. Milewski, Handbook of Fillers and Reinforcements for Plastics, Van Nostrand, New York (1978).

13. C. DeArmitt, Plast. Additives Compound., 5, 28 (2001).

14. B. Weidenfeller, M. Höfer and F. Schilling, Composites, A33, 1041 (2002).

15. B. Weidenfeller, M. Höfer and F. Schilling, Composites, A35, 423 (2004).

16. C. P. Wong and R. S. Bollampally, J. Appl. Polym. Sci., 74, 3396 (1999).

17. B. Weidenfeller, M. Höfer and F. Schilling, Composites, A36, 345 (2005).

18. G. Bertelli, G. Camino, E. Marchetti, L. Costa, E. Casorati and R. Locatelli, Polym. Degrad. Stabil., 25, 277 (1989).

19. J. L. Acosta, M. Rodriguez, A. Linares and J. R. Jurado, Polym. Bull., 24, 87 (1990).

20. X. Almeras, M. Le Bras, F. Poutch, S. Bourbigot, G. Marosi and P. Anna, Macromol. Symp., 198, 435 (2003).

21. X. Almeras, M. Le Bras, P. Hornsby, S. Bourbigot, Gy. Marosi, S. Keszei and F. Poutch, Polym. Degrad. Stabil., 82, 325 (2003).

22. Y. Fukushima and S. Inagaki, J. Inclusion Phenom., 5, 473 (1987).

23. Y. Fukushima, A. Okada, M. Kawasumi, T. Kurauchi and O. Kamigaito, Clay Minerals, 23, 27 (1988).

24. A. Usuki, Y. Kojima, M. Kawasumi, A. Okada, Y. Fukushima, T. Kurauchi and O. Kamigaito, J. Mater. Res., 8, 1179 (1993). 
25. S. S. Ray and M. Okamoto, Prog. Polym. Sci., 28, 1539 (2003).

26. E. P. Giannelis, Appl. Organomet. Chem., 12, 675 (1998).

27. P. C. LeBaron, Z. Wang and T. J. Pinnavaia, Appl. Clay Sci., 15, 11 (1999).

28. T. J. Pinnavaia and G. W. Beall, Polymer-Clay Nanocomposites, Wiley, New York (2001).

29. H. Fischer, Mater. Sci. Eng., C23, 763 (2003).

30. A. K. Bledzki and J. Gassan, Prog. Polym. Sci., 24, 221 (1999).

31. A. K. Bledzki, O. Faruk and M. Huque, Polym. Plast. Technol. Eng., 41, 435 (2002).

32. A. K. Bledzki, M. Letman, A. Viksne and L. Rence, Composites, A36, 789 (2005).

33. A. K. Bledzki, S. Reihmane and J. Gassan, Polym. Plast. Technol. Eng., 37,451 (1998).

34. J. Markarian, Plast. Additives Compound, 4, 18 (2002).

35. G. Pritchard, Plast. Additives Compound, 6, 18 (2004).

36. A. Jacob, Reinf. Plast., 50, 32 (2006).

37. A. K. Bledzki, O. Faruk and V. E. Sperber, Macromol. Mater. Eng., 291, 449 (2006).

38. M. Arroyo, F. Perez and J. P. Vigo, J. Appl. Polym. Sci., 32, 5105 (1986).

39. J. L. Acosta, C. R. Herrero and E. Morales, Eur. Polym. J., 27, 11 (1991).

40. E. Morales, M. C. Ojeda, A. Linares and J. L. Acosta, Polym. Eng. Sci., 32, 769 (1992).

41. L. Gonzalez, A. Rodriguez, A. Marcos-Fernandez and A. Del Campo, J. Adhes. Sci. Technol., 11, 247 (1997).

42. L. Bokobza, J. Appl. Polym. Sci., 93, 2095 (2004).

43. L. Bokobza, A. Burr, G. Garnaud, M. Y. Perrin and S. Pagnotta, Polym. Int., 53, 1060 (2004). 
44. M. D. Landete-Ruiz and J. M. Martin-Martinez, Macromol. Symp., 221, 43 (2005).

45. E. Bilotti, H. R. Fischer and T. Peijs, J. Appl. Polym. Sci., 107, 1116 (2008).

46. E. Morales and J. R. White, J. Mater. Sci., 23, 3612 (1988).

47. M. Arroyo, A. Iglesias and F. Perez, J. Appl. Polym. Sci., 30, 2475 (1985).

48. D. P. N. Vlasveld, M. de Jong, H. E. N. Bersee, A. D. Gotsis, S. J. Picken, Polymer, 46, 10279 (2005).

49. L. Bokobza, J. P. Chauvin, Polymer, 46, 4144 (2005).

50. B. Pukánszky, in Handbook of Polyolefins, C. Vasile Ed., pp. 689-722, Marcel Dekker, New York (2000).

51. A. Krysztafkiewicz, Surface. Coatings Technol., 35, 151 (1988).

52. G. Vörös, E. Fekete and B. Pukánszky, J. Adhesion., 64, 229 (1997).

53. B. Pukánszky, B. Turcsányi and F. Tüdős, in Interfaces in Polymer, Ceramic, and Metal Matrix Composites, H. Ishida Ed., pp. 467-475, Elsevier, New York (1988).

54. B. Pukánszky, Composites, 21, 255 (1990).

55. P. Vollenberg, D. Heikens and H. C. B. Ladan, Polym Compos., 9, 382 (1988).

56. B. Pukánszky and G. Vörös, Compos. Interfaces, 1, 411 (1993).

57. H. P. Schlumpf, Chimia, 44, 359 (1990).

58. R. N. Rothon, Particulate-filled polymer composites, Rapra Technology, Shrewsbury (2003).

59. L. E. Nielsen, Mechanical properties of polymers and composites, Marcel Dekker, New York (1974).

60. R. J. Samuels, Structured Polymer Properties, John Wiley, New York, (1974).

61. B. Pukánszky, I. Mudra and P. Staniek, J. Vinyl Additive Technol. 3, 53 (1997).

62. L. Bartosiewicz and C. J. Kelly, Adv. Polym. Technol., 7, 21 (1987).

63. A. M. Riley, C. D. Paynter, P. M. McGenity and J. M. Adams, Plast. Rubber Process. Appl., 14, 85 (1990). 
64. J. Menczel and J. Varga, J. Thermal. Anal., 28161 (1983).

65. M. Fujiyama and T. Wakino, J. Appl. Polym. Sci., 42, 2739 (1991).

66. A. Pozsgay, T. Fráter, L. Papp, I. Sajó, and B. Pukánszky, J. Macromol. Sci., B41, 1249 (2002).

67. P. Kodgire, R. Kalgaonkar, S. Hambir, N. Bulakh and J. P. Jog, J. Appl. Polym. Sci., 81, 1786 (2001).

68. P. Maiti, P. H. Nam, M. Okamoto, N. Hasegawa and A. Usuki, Macromolecules, 35, 2042 (2002).

69. P. H. Nam, P. Maiti, M. Okamoto, T. Kotaka, N. Hasegawa and A. Usuki, Polymer, 42, 9633 (2001).

70. V. V. Ray, A. K. Banthia and C. Schick, Polymer, 48, 2404 (2007).

71. M. Avella, S. Cosco, M. L. Di Lorenzo, E. Di Pace, M. E. Errico and G. Gentile, Eur. Polym. J., 42, 1548 (2006).

72. F. Rybnikar, J. Appl. Polym. Sci., 42, 2727 (1991).

73. A. Garton, S. W. Kim and D. M. Wiles, J. Polym. Sci., Polym. Lett., 20, 273 (1982)

74. D. Zuchowska and D. Hlavatá, Eur. Polym. J., 27, 355 (1991).

75. P. Bajaj, N. K. Jha, P. L Maurya and A. C. Misra, J. Appl. Polym. Sci., 34, 1785 (1987).

76. J. Varga and F. Schulek-Tóth, Angew. Macromol. Chem., 188, 11 (1991).

77. J. Varga, J. Polym. Eng., 1, 231 (1991).

78. J. Varga and F. Schulek-Tóth, Angew. Makromol. Chem., 188, 11 (1991).

79. J. Varga, J. Thermal. Anal., 35, 1891 (1989).

80. H. E. Miltner, H. Rahier, A. Pozsgay, B. Pukánszky and B. van Mele, Compos. Interfaces, 12, 787 (2005).

81. H. E. Miltner, G. van Assche, A. Pozsgay, B. Pukánszky and B. van Mele, Polymer, 47, 826 (2006). 
82. Y. Kojima, A. Usuki, M. Kawasumi, A. Okada, T. Kurauchi, O. Kamigaito and K. Kaji, J. Polym. Sci., B32, 625 (1994).

83. T. M. Wu and C. S. Liao, Macromol. Chem. Phys., 201, 2820 (2000).

84. X. Liu, Q. Wu, Eur. Polym. J., 38, 1383 (2002).

85. D. M. Lincoln, R. A. Vaia, Z. G. Wang, B. S. Hsiao and R. Krishnamoorti, Polymer, 42, 9975 (2001).

86. D. S. Homminga, B. Goderis, V. B. F. Mathot and G. Groeninckx, Polymer, 47, 1630 (2006).

87. J. S. Choi, S. T. Lim, H. J. Choi, A. Pozsgay and L. Százdi, Compos. Interfaces, 13, 773 (2006).

88. K. Kendall, Br. Polym. J., 10, 35 (1978).

89. S. N. Maiti and P. K. Mahapatro, J. Appl. Polym. Sci., 37, 1889 (1989).

90. S. N. Maiti and P. K. Mahapatro, Int. J. Polym. Mater., 14, 205 (1990).

91. T. J. Hutley and M. W. Darlington, Polym. Commun., 25, 226 (1984).

92. T. J. Hutley and M. W. Darlington, Polym. Commun., 26, 264 (1985).

93. B. Pukánszky, K. Belina, A. Rockenbauer and F. H. J. Maurer, Composites, 25, 205 (1994).

94. B. Pukánszky and J. Móczó, Macromol. Symp. 214, 115 (2004).

95. S. F. Xavier and Y. N. Sharma, Angew. Makromol. Chem., 127, 145 (1984).

96. P. Singh and M. R. Kamal, Polym. Compos., 10, 344 (1989).

97. M. J. Folkes and W. K. Wong, Polymer, 28, 1309 (1987).

98. M. J. Folkes and S. T. Hardwick, J. Mater. Sci. Lett., 6, 656 (1987).

99. A. Golovoy, Polym. Compos., 7, 405 (1986).

100. M. J. Voelker, Polym. Compos., 12, 119 (1991)

101. P. H. T. Vollenberg and D. Heikens, in Composite Interfaces, H. Ishida and J. L. Koenig Ed., pp. 171-175, Elsevier, New York (1986). 
102. F. Ramsteiner and R. Theysohn, Composites, 15, 121 (1984).

103. E. A. A. van Hartingsveldt and J. J. van Aartsen, Polymer, 30, 1984 (1989).

104. G. Boven, R. Folkersma, G. Challa, A. J. Scouten and M. Bosma, Polymer, 33, 83 (1992).

105. A. Meddad and B. Fisa, J. Appl. Polym. Sci., 64, 653 (1997).

106. L. E. Asp, B. A. Sjögren and L. A. Berglund, Polym. Compos., 18, 9 (1997).

107. B. A. Sjögren and L. A. Berglund, Polym. Compos., 18, 1 (1997).

108. C. P. Tsui, C. Y. Tang and T. C. Lee, Polym. Compos., 22, 742 (2001).

109. A. Meddad and B. Fisa, J. Appl. Polym. Sci., 65, 2013 (1997).

110. I. L. Dubnikova, S. M. Berezina and A. V. Antonov, J. Appl. Polym. Sci., 85, 1911 (2002).

111. S. Miyata, T. Imahashi and H. Aabuki, J. Appl. Polym. Sci., 25, 415 (1980).

112. P. R. Hornsby and C. L. Watson, Plast. Rubber Process. Appl., 11, 45 (1989).

113. J. I. Velasco, C. Morhain, A. B. Martínez, M. A. Rodríguez-Pérez and J. A. de Saja, Polymer, 43, 6805 (2002).

114. J. I. Velasco, C. Morhain, A. B. Martínez, M. A. Rodríguez-Pérez and J. A. de Saja, Polymer, 43, 6813 (2002).

115. L. Dányádi, K. Renner, Z. Szabó, G. Nagy, J. Móczó and B. Pukánszky, Polym. Adv. Technol., 17, 967 (2006).

116. L. Dányádi, K. Renner, J. Móczó and B. Pukánszky, Polym. Eng. Sci., 47, 1246 (2007).

117. L. Dányádi, T. Janecska, Z. Szabó, G. Nagy, J. Móczó and B. Pukánszky, Compos. Sci. Technol., 67, 2838 (2007)

118. R. S. Hadal, A. Dasari, J. Rohrmann, R. D. K. Misra, Mater. Sci. Eng., A372, 296 (2004).

119. A. Dasari, R. D. K. Misra, Acta Materialia, 52, 1683 (2004). 
120. R. Hadal, A. Dasari, J. Rohrmann and R. D. K. Misra, Mater. Sci. Eng. A380, 326 (2004).

121. M. Murariu, A. Da Silva Ferreira, P. Degée, M. Alexandre and P. Dubois, Polymer, 48, $2613(2007)$

122. M. Pluta, M. Murariu, A. Da Silva Ferreira, M. Alexandre, A Galeski and P. Dubois, J. Polym. Sci., Polym. Phys., 45, 2770 (2007)

123. D. M. Bigg, Polym. Compos., 8, 115 (1987).

124. B. Bridge, M. J. Folkes and H. Jahankhani, J. Mater. Sci., 23, 1948 (1988).

125. L. S. Chen, Y. W. Mai and B. Cotterell, Polym. Eng. Sci., 29, 505 (1989).

126. K. Mitsuishi, S. Kodama and H. Kawasaki, Polym. Eng. Sci., 25, 1069 (1985).

127. L. E. Nielsen and R. F. Landel, Mechanical properties of polymers and composites, Marcel Dekker, New York (1993).

128. D. Bezard, Oesterr. Kunstst. Z., 17, 174 (1986).

129. Y. Suetsugu, T. Kikutani, T. Kyu and J. L. White, Colloid. Polym. Sci., 268, 118 (1990).

130. Y. Suetsugu and J. L. White, Adv. Polym. Technol., 7, 427 (1987).

131. P. Mareri, S. Bastide, N. Binda and A. Crespy, Compos. Sci. Technol. 58, 747 (1998)

132. T. Xu, H. Lei, and C. S. Xie, Polym. Testing, 21, 319 (2002)

133. V. Svehlova and E. Poloucek, Angew. Makromol. Chem., 153, 197 (1987).

134. E. Fekete, Sz. Molnár, G. M. Kim, G. H. Michler and B. Pukánszky, J. Macromol. Sci. Phys., B38, 885 (1999).

135. B. Pukánszky, E. Fekete and F. Tüdős, Makromol. Chem., Macromol. Symp., 28, 165 (1989).

136. K. Okuno and R. T. Woodhams, Polym Eng. Sci., 15, 308 (1975).

137. B. Pukánszky, F. Tüdős, J. Jancar and J. Kolarík, J. Mater. Sci. Lett., 8, 1040 
(1989).

138. C. Busigin, R. Lahtinen, G. M. Martinez, G. Thomas and R. T. Woodhams, Polym. Eng. Sci., 24, 169 (1984).

139. L. M. Parrinello, Tappi J., 74, 85 (1991).

140. J. P. Trotignon, J. Verdu, R. De Boissard and A. De Vallois, in Polymer Composites, B. Sedlácek Ed., pp. 191-198, Walter de Gruyter, Berlin (1986).

141. H. Ishida and J. D. Miller, Macromolecules, 17, 1659 (1984).

142. K. Stoklasa, F. Tomis and Z. Navratil, Thermochim. Acta, 93, 221 (1985).

143. G. M. Kerch and L. Irgens, Thermochim. Acta, 93, 155 (1985).

144. J. Kubát and Á. Szalánczi, Polym. Eng. Sci., 14, 873 (1974)

145. J. Karger-Kocsis and I. Csikai, Polym. Eng. Sci., 27, 241 (1987)

146. V. B. Gupta, R. K. Mittal and P. K. Sharma, Polym. Compos., 10, 8 (1989).

147. S. E. Tausz and C. E. Chaffey, J. Appl. Polym. Sci., 27, 4493 (1982).

148. P. R. Hornsby, in Particulate-Filled Polymer Composites, R. N. Rothon Ed., pp. 207-261, Rapra Technology, Shrewsbury (2003).

149. M. J. Adams, M. A. Mullier and J. P. K. Seville, in Tribology in particulate technology, B. J. Briscoe and M. J. Adams Ed., pp. 375-389, Adam Hilger, Bristol (1987).

150. D. Tabor, in Tribology in particulate technology, B. J. Briscoe and M. J. Adams Ed., pp. 206-219, Adam Hilger, Bristol (1987).

151. M. J. Adams and B. Edmondson, in Tribology in particulate technology, B. J. Briscoe and M. J. Adams Ed., pp. 154-172, Adam Hilger, Bristol (1987).

152. W. Balachandran, in Tribology in particulate technology, B. J. Briscoe and M. J. Adams Ed., pp. 135-153, Adam Hilger, Bristol (1987).

153. S. L. Goren, J. Colloid. Interface. Sci., 36, 94 (1971)

154. B. Pukánszky and E. Fekete, Adv. Polym. Sci., 139, 109 (1999). 
155. B. Pukánszky and E. Fekete, Polym. Polym. Compos., 6, 313 (1998).

156. M. R. Kamal, L. Song and P. Singh, Polym. Compos., 7, 323 (1986).

157. M. Sanou, B. Chung and C. Cohen, Polym. Eng. Sci., 25, 1008 (1985).

158. F. Lisy, A. Hiltner and E. Baer, Polym. Prepr., 32, 21 (1991).

159. A. Rockenbauer, L. Jókay, B. Pukánszky and F. Tüdős, Macromolecules, 18, 918 (1985).

160. M. Fujiyama and T. Wakino, J. Appl. Polym. Sci., 42, 9 (1991).

161. G. A. Bihlmayer, G. Aumayr and F. Mautner, Plaste Kautsch., 35, 185 (1988).

162. R. K. Mittal, V. B. Gupta and P. Sharma, J. Mater. Sci., 22, 1949 (1987).

163. T. Vu-Khanh and B. Fisa, Polym. Compos., 7, 219 (1986).

164. M. Christie, Plast. Eng., 42, 41 (1986).

165. B. Sanschagrin, R. Gauvin, B. Fisa and T. Vu Khanh, Plast. Compd., 10, 37-38, 40, 42-43, 45, 48 (1987).

166. K. B. Fisa, J. Dufour and T. Vu-Khanh, Polym. Compos., 8, 408 (1987).

167. A Vaxman and M. Narkis, Polym. Compos., 12, 161 (1991).

168. K. W. Allen, Phys. Technol., 19, 234 (1988).

169. S. Wu in Polymer blends, D. R. Paul and S. Newman Ed., pp. 243, Academic Press, New York (1978).

170. K. W. Allen, J. Adhesion, 21, 261 (1987).

171. B. V. Derjaugin, Research, 8, 365 (1955).

172. H. P. Schreiber, in The interfacial interactions in polymeric composites, G. Akovali Ed., pp. 21-59, Kluwer, Amsterdam (1993).

173. F. M. Fowkes, Ind. Eng. Chem., 56, 40 (1964).

174. F. M. Fowkes in Hydrophobic surfaces, F. M. Fowkes Ed., pp. 151-163, Academic Press, New York (1969).

175. S. Wu, J. Macromol. Sci., Rev. Macromol Chem., C6, 85 (1974). 
176. K. L Mittal and H. R. Anderson, Acid-base interactions, relevance to adhesion science and technology, VSP, Utrecht (1991).

177. F. M. Fowkes, in Physicochemical aspects of polymer surfaces, K. L. Mittal Ed., pp. 583-603, Plenum, New York, (1981).

178. F. M. Fowkes, in Acid-base interactions, relevance to adhesion science and technology, K. L Mittal and H. R. Anderson Ed., p. 93-115, VSP, Utrecht (1991).

179. R. S. Drago, G. C. Vogel and T. E. Needham, J. Am. Chem. Soc., 93, 6014 (1971).

180. V. Gutmann, The donor-acceptor approach to molecular interactions, Plenum, New York (1978).

181. E. Fekete, J. Móczó and B. Pukánszky, J. Colloid Interface Sci., 269, 143 (2004).

182. B. Pukánszky and F. H. J. Maurer, Polymer, 36, 1617 (1995).

183. C. Y. Yue and W. L. Cheung, J. Mater. Sci., 26, 870 (1991).

184. P. H. T. Vollenberg and D. Heikens, Polymer, 30, 1656 (1989).

185. J. E. Stamhuis and J. P. A. Loppé, Rheol. Acta, 21, 103 (1982).

186. M. Sumita, H. Tsukini, K. Miyasaka and K. Ishikawa, J. Appl. Polym. Sci., 29, 1523 (1984).

187. F. R. Jones, in Interfacial Phenomena in Composite Materials, F. R. Jones Ed., p. 2532, Butterworths, London (1989)

188. F. H. J. Maurer, R Kosfeld and T. Uhlenbroich, Colloid. Polym. Sci., 263, 624 (1985).

189. C. Scott, H. Ishida and F. H. J. Maurer, J. Mater. Sci., 22, 3963 (1987).

190. J. D. Miller, H. Ishida and F. H. J. Maurer, Rheol. Acta, 27, 397 (1988).

191. P. S. Theocaris and P. H. I. Ponirides, J. Appl. Polym. Sci., 32, 6267 (1986).

192. E. Sideridis, P. S. Theocaris and G. C. Papanicolaou, Rheol. Acta, 25, 350 (1986).

193. W. Wu, C. F. Majkrzak, S. K. Satija, J. F. Ankver, W. J. Orts, M. Satkowski and S. D. Smith, Polym. Commun., 33, 5081 (1992). 
194. F. H. J. Maurer in Polymer composites, B. Sedlacek Ed., p. 399-411., Walter de Gruyter, Berlin, (1986).

195. S. N. Maiti and P. K. Mahapatro, J. Appl. Polym. Sci., 42, 3101 (1991).

196. G. Vörös and B. Pukánszky, J. Mater. Sci., 30, 4171 (1995).

197. G. Vörös and B. Pukánszky, Composites, A32, 343 (2001).

198. G. Vörös and B. Pukánszky, Composites, A33, 1317 (2002).

199. G. Akay, Polym. Eng. Sci., 30, 1361 (1990).

200. K. F. Mansfield and D. N. Theodorou, Macromolecules, 24, 4295 (1991).

201. F. H. J. Maurer, H. M. Schoffeleers, R. Kosfeld and T. Uhlenbroich, in Progress in Science and Engineering of Composites, T. Hayashi, K. Kawata and S. Umekawa Ed., p. 803-809, ICCM-IV, Tokyo (1982).

202. K. Iisaka and K. Shibayama, J. Appl. Polym. Sci., 22, 3135 (1978).

203. E. K. Drown, H. Al Moussawi and L. T. Drzal, J. Adhes. Sci. Technol., 5, 865 (1991).

204. M. Labronici and H. Ishida, Compos. Interfaces, 2, 199 (1994).

205. D. J. Bannister, M. C. Andrews, A. J. Cervenka and R. J. Young, Compos. Sci. Technol., 53, 411 (1995).

206. E. Pisanova and E. Mäder, J. Adhes. Sci. Technol., 14, 415 (2000).

207. J. Móczó, E. Fekete and B. Pukánszky, J. Adhesion, 78, 861 (2002).

208. B. Pukánszky and F. Tüdős, in Controlled Interphases in Composite Materials, H. Ishida Ed., p. 691-700, Elsevier, (1990).

209. B. Pukánszky, New Polym. Mater., 3, 205 (1992).

210. J. M. Felix and P. Gatenholm, J. Appl. Polym. Sci., 42, 609 (1991).

211. W. Gutowski, in Controlled Interphases in Composite Materials, H. Ishida Ed., pp. 505-520, Elsevier, New York 1990.

212. H. W. Fox, E. F. Hare and W. A. Zismann, J. Phys. Chem., 59, 1097 (1955). 
213. J. R. Huntsberger, J. Adhesion, 12, 3 (1981).

214. J. Móczó, E. Fekete and B. Pukánszky, Progr. Colloid Polym. Sci.,. 125, 134 (2004).

215. J. Jancár and J. Kucera, Polym. Eng. Sci., 30, 707 (1990).

216. J. Jancár, J. Mater. Sci., 24, 3947 (1989).

217. E. Fekete, B. Pukánszky, A. Tóth and I. Bertóti, J. Colloid Interface Sci., 135, 200, (1990).

218. G. Marosi, G. Bertalan, I. Rusznák and P. Anna, Colloids Surf., 23, 185 (1987)

219. P. Bajaj, N. K. Jha and R. K. Jha, Polym. Eng. Sci., 29, 557 (1989).

220. P. Bajaj, N. K. Jha and R. K. Jha, Br. Polym. J., 21, 345 (1989).

221. R. G. Raj, B. V. Kokta, F. Dembele and B. Sanschagrin, J. Appl. Polym. Sci., 38, 1987 (1989).

222. E. Papirer, J. Schultz and C. Turchi, Eur. Polym. J., 12, 1155 (1984).

223. R. C. Allard, T. Vu-Khanh and J. P. Chalifoux, Polym. Compos., 10, 62 (1989).

224. M. Bramuzzo, A. Savadori and D. Bacci, Polym. Compos., 6, 1 (1985).

225. J. Spanoudakis and R. J. Young, J. Mater. Sci. 19, 487 (1984)

226. H. Ishida and J. L. Koenig, J. Polym. Sci., Polym. Phys., 18, 1931 (1980).

227. E. P. Plueddemann, Silane coupling agents, Plenum, New York (1982).

228. H. Yazdani, J. Morshedian, H. A. Khonakdar, Polym. Compos., 27, 614 (2006)

229. L. J. Matienzo and T. K. Shah, Surf. Interface Anal., 8, 53 (1986).

230. P. H. T. Vollenberg and D. Heikens, J. Mater. Sci., 25, 3089 (1990).

231. R. G. Raj, B. V. Kokta, and C. Daneault, Int. J. Polym. Mater., 12, 239 (1989).

232. E. Mäder and K. H. Freitag, Composites, 21, 397 (1990).

233. Z. Demjén, B. Pukánszky, E. Földes and J. Nagy, J. Interface Colloid Sci., 194, 269 (1997).

234. E. J. Sadler and A. C. Vecere, Plast. Rubber Process Appl., 24, 271 (1995).

235. M. Zolotnitsky and J. R. Steinmetz, J. Vinyl. Additive. Technol., 1, 109 (1995). 
236. B. Widmann, H. G. Fritz and H. Oggermüller, Kunststoffe German Plast., 82, 16 (1992).

237. Z. Demjén, B. Pukánszky and J. Jr. Nagy, Polymer, 40, 1763 (1998).

238. S. Takase and N. Shiraishi, J. Appl. Polym. Sci., 37, 645 (1989).

239. J. Jancar, M. Kummer. and J. Kolarík, in Interfaces in Polymer, Ceramic, and Metal Matrix Composites, H. Ishida Ed., pp. 705-711, Elsevier, New York (1988).

240. J. M. Felix and P. Gatenholm, J. Appl. Polym. Sci., 50, 699 (1991).

241. I. Kelnar, Angew. Makromol. Chem., 189, 207 (1991).

242. W. Y. Chiang and W. D. Yang, J. Appl. Polym. Sci., 35, 807 (1988).

243. J. Jancár and J. Kucera, Polym. Eng. Sci., 30, 714 (1990).

244. J. N. Goodier, J. Appl. Mech., 55, 39 (1933).

245. T. Kowalewski, A. Galeski and M. Kryszewski, in Polymer Blends. Processing, Morphology and Properties, M. Kryszewski, A. Galeski and E. Martuscelli Ed., pp. 223-241, Plenum, New York, (1984).

246. P. H. T. Vollenberg, Ph.D. Thesis, Eindhoven University of Technology, Eindhoven, (1987).

247. C. B. Bucknall, Toughened Plastics, Applied Sci. Publ., London, (1977).

248. E. Nezbedová and I. Davidovic, Plaste Kautsch., 33, 228 (1986).

249. E. A. A. Hartingsveldt, Ph.D. Thesis, Technical University of Delft, (1987).

250. R. H. Beck, S. Gratch, S. Newman and K. C. Rausch, J. Polym. Sci., Polym. Lett., 6, 707 (1968).

251. A. Galeski and R. Kalinski, in Polymer Blends. Processing, Morphology and Properties, E. Martuscelli, R. Palumbo and M. Kryszewski Ed., pp. 431-449, Plenum, New York (1980).

252. B. Pukánszky, M. van Es, F. H. J. Maurer and G. Vörös, J. Mater. Sci., 29, 2350 (1994). 
253. A. Sudár, J. Móczó, G. Vörös and B. Pukánszky, Express Polym. Lett., 1, 763, (2007).

254. H. Nakagawa and H. Sano, Polym. Prepr., 26, 249 (1985).

255. G. G. Trantina, Polym. Eng. Sci., 24, 1180 (1984).

256. L. Nicolais and L. Nicodemo, Intern. J. Polym. Mater., 4, 229 (1974)

257. A. Lazzeri and C. B. Bucknall, J. Mater. Sci., 28, 6799 (1993).

258. R. J. Farris, Trans. Soc. Rheol., 12,315 (1968).

259. B. Pukánszky and G. Vörös, Polym. Compos. 17, 384 (1996).

260. J. W. Ess and P. R. Hornsby, Polym. Test., 6, 205 (1986).

261. G. M. Kim and D. H. Lee, J. Appl. Polym. Sci., 82, 785 (2001).

262. G. M. Kim and G. H. Michler, Polymer, 39, 5699 (1998).

263. J. Kolarík, F. Lednický and B. Pukánszky, in Proceedings of $6^{\text {th }} I C C M / 2^{\text {nd }} E C C M, \mathrm{~F}$.

L. Matthews, N. C. R. Buskell, J. M. Hodgkinson and J. Morton Eds., pp. 452-461, Elsevier, London (1987).

264. A. J. Kinloch and R. J. Young, Fracture Behaviour of Polymers, Elsevier, London (1983).

265. H. Breuer, NATO ASI Ser., Ser. E, 89, 375 (1985).

266. H. Breuer, NATO ASI Ser., Ser. E, 89, 383 (1985).

267. M. E. J. Dekkers and D. Heikens, J. Mater. Sci., 20, 3873 (1985).

268. M. E. J. Dekkers and D. Heikens, J. Mater. Sci., 19, 3271 (1984).

269. S. S. Sternstein and L. Ongchin, ACS Polym. Prepr., 10, 1117 (1969)

270. C. D. Han, J. Appl. Polym. Sci., 18, 821 (1974).

271. D. L. Faulkner and L. R. Schmidt, Polym. Eng. Sci., 17, 657 (1977).

272. D. J. Jeffrey and A. Acrivos, AIChE J., 22, 417 (1976).

273. V. P. Juskey and C. E. Chaffey, Canadian J. Chem. Eng., 60, 334 (1982).

274. L. A. Utracki, Rubber Chem. Technol., 57, 507 (1984). 
275. M. R. Kamal, A. T. Mutel and L. A. Utracki, Polymer. Compos., 5, 289 (1984).

276. L. A. Utracki, in Proc. IX. Intl. Congress on Rheology, pp. 467-474, Mexico, (1984).

277. S. McGee and R. L. McCullough, Polym. Compos., 2, 149 (1981).

278. R. A. Dickie, in Polymer Blends, D. R. Paul and S. Newman Eds., pp. 353-391, Academic Press, New York (1978).

279. S. Ahmed and F. R. Jones, J. Mater. Sci., 25, 4933 (1990).

280. R. M. Christensen and K. H. Lo, J. Mech. Phys. Solids, 27, 315 (1979).

281. T. R. Lewis and L. E. Nielsen, J. Appl. Polym. Sci., 14, 1449 (1970).

282. V. P. Chacko, F. E. Karasz and R. J. Farris, Polym. Eng. Sci., 15, 968 (1982).

283. R. G. Raj, B. V. Kokta, F. Dembele and B. Sanschagrin, J. Appl. Polym. Sci., 38, 1987 (1989).

284. T. Vu-Khanh, B. Sanschagrin and B. Fisa, Polym. Compos., 6, 249 (1985).

285. L. Nicolais and M. Narkis, Polym. Eng. Sci., 11, 194 (1971).

286. O. Ishai and L. J. Cohen, J. Compos. Mater., 2, 302 (1968).

287. B. Turcsányi, B. Pukánszky and F. Tüdős, J. Mater. Sci. Lett. 7, 160 (1988)

288. B. V. Kokta, R. G. Raj and C. Daneault, Polym. Plast. Technol. Eng., 28, 247 (1989)

289. L. Nicolais and L. Nicodemo, Polym. Eng. Sci., 13, 469 (1973).

290. L. Százdi, B. Jr. Pukánszky, G. J. Vancso and B. Pukánszky, Polymer 47, 4638 (2006).

291. L. Százdi, A. Pozsgay and B. Pukánszky, Eur. Polym. J. 43, 345 (2007).

292. S. K. Brown, Br. Polym. J., 12, 24 (1980).

293. Sz. Molnár, B. Pukánszky, C. O. Hammer and F. H. J. Maurer, Polymer, 41, 1529 (2000).

294. C. B. Bucknall. Adv. Polym. Sci., 27, 121 (1978). 
295. K. Friedrich and U. A. Karsch, Fibre Sci. Technol., 18, 37 (1983).

296. F. F. Lange, Phil. Mag., 22, 983 (1970).

297. A. G. Evans, Phil. Mag., 26, 1327 (1972).

298. A. G. Evans, S. Williams and P. W. R. Beaumont, J. Mater. Sci., 20, 3668 (1985).

299. J. Jancar, A. T. DiBenedetto and A. DiAnselmo, Polym. Eng. Sci., 33, 559 (1993).

300. L. E. Nielsen, J. Macromol. Sci., A1, 929 (1967).

301. R. K. Bharadwaj, Macromolecules, 34, 9189 (2001).

302. K. Yano, A. Usuki, A. Okada, T. Kurauchi and O. Kamigaito, J. Polym. Sci., A31, 2493 (1993).

303. K. Yano, A. Usuki and A. Okada, J. Polym. Sci., A35, 2289 (1997).

304. M. A. Osman, J. E. P. Rupp and U. W. Suter, J. Mater. Chem., 15, 1298 (2005).

305. R. N. Rothon, in Particulate-Filled Polymer Composites, R. N. Rothon Ed., pp. 263-302, Rapra Technology, Shrewsbury (2003).

306. P. Pötschke, A. R. Bhattacharyya, A. Janke, S. Pegel, A. Leonhardt, Ch. Täschner, M. Ritschel, S. Roth, B. Hornbostel and J. Cech, Fullerenes, Nanotubes, Carbon Nanostructures, 13, Suppl. 1, 211 (2005).

307. P. Pötschke, B. Kretzschmar and A. Janke, Compos. Sci. Technol., 67, 855 (2007).

308. D. Stauffer and A. Aharony, Introduction to Percolation Theory, Taylor and Francis, London (1992).

309. S. Barrau, P. Demont, A. Peigney, C. Laurent and C. Lacabanne, Macromolecules, 36, 5187 (2003).

310. J. Karger-Kocsis, A. Kalló and V. N. Kuleznev, Polymer, 25, 279 (1984).

311. C. Bonnerup and P. Gatenfolm, J. Adhesion. Sci. Technol., 7, 247 (1993).

312. J. Kolarík and F. Lednický, in Polymer Composites, B. Sedlácek Ed., pp. 537-544, Walter de Gruyter, Berlin (1986).

313. K. Premphet and P. Horanont, J. Appl. Polym. Sci., 74, 3445 (1999). 
314. P. R. Hornsby and K. Premphet, J. Appl. Polym. Sci., 70, 587 (1998).

315. B. Pukánszky, J. Kolaric and F. Lednicky, in Polymer Composites, B. Sedlácek Ed., pp. 553-559, Walter de Gruyter, Berlin (1986)

316. J. E. Stamhuis, Polym. Compos., 5, 202 (1984).

317. J. E. Stamhuis, Polym. Compos., 9, 72 (1988).

318. J. E. Stamhuis, Polym. Compos., 9, 280 (1988).

319. B. Pukánszky, F. Tüdős, J. Kolarík and F. Lednický, Polym Compos., 11, 98 (1990).

320. C.O. Hammer, F. H. J. Maurer, Sz. Molnár and B. Pukánszky, J. Mater Sci. 34, 5911 (1999).

321. W. Y. Chiang, W. D. Yang and B. Pukánszky, Polym. Eng. Sci., 32, 641 (1992).

322. J. Kolarík, F. Lednický, J. Jancar and B. Pukánszky, Polym. Commun., 31, 201 (1990).

323. B. Pukánszky, F. Tüdős, J. Kolarík and F. Lednický, Compos. Polym., 2, 491 (1989).

324. B. Pukánszky, Eur. Polym. J., 41, 645 (2005).

325. Y. Kojima, A. Usuki, M. Kawasumi, A. Okada, Y. Fukushima, T. Kurauchi and O. Kamigaito, J. Mater. Res., 8, 1185 (1993).

326. M. W. Noh and D. C. Lee, Polym. Bull., 42, 619 (1999).

327. H. Wang, C. C. Zeng, M. Elkovitch, L. J. Lee and K. W. Koelling, Polym. Eng. Sci., 41, 2036 (2001).

328. A. Pozsgay, I. Csapó, L. Százdi and B. Pukánszky, Mater. Res. Innov., 8, 138 (2004).

329. M. Q. Yuan, X. J. Pan and C. Y. Wan, Polym. Polym. Compos., 12, 619 (2004).

330. M. A. Osman, J. E. P. Rupp and U. W. Suter, Polymer, 46, 1653 (2005).

331. T. S. Ellis and J. S. D'Angelo, J. Appl. Polym. Sci., 90, 1639 (2003). 
332. A. Oya, Y. Kurokawa and H. Yasuda, J. Mater. Sci., 35, 1045 (2000).

333. M. Kato, H. Okamoto, N. Hasegawa, A. Tsukigase and A. Usuki, Polym. Eng. Sci., 43, 1312 (2003).

334. P. Reichert, H. Nitz, S. Klinke, R. Brandsch, R. Thomann and R. Mülhaupt, Macromol. Mater. Eng., 275, 8 (2000).

335. J. W. Jordan, J. Phys. Colloid Chem., 53, 294 (1949).

336. F. Kádár, L. Százdi, E. Fekete and B. Pukánszky, Langmuir, 22, 7848 (2006).

337. Y. H. Hyun, S. T. Lim, H. J. Choi and M. S. Jhon, Macromolecules, 34, 3804 (2001)

338. T. D. Fornes and D. R. Paul, Polymer, 44, 4993 (2003).

339. R. A. Vaia and E. P. Giannelis, Macromolecules, 30, 7990 (1997).

340. S. T. Lim, H. H. Yang, H. J. Choi and M. S. Jhon, Chem. Mater., 14, 1839 [2002]

341. S. T. Lim, C. H. Lee, H. J. Choi and M. S. Jhon, J. Polym. Sci., Polym. Phys., B41, $2052(2003)$

342. C. H. Lee, H. B. Kim, S. T. Lim, H. S. Kim, Y. K. Kwon and H. J. Choi, Macromol. Chem. Phys., 207, 444 (2006)

343. T. H. Kim, L. W. Jang, D. C. Lee, H. J. Choi and M. S. Jhon, Macromol. Rapid. Commun., 23, 191 (2002)

344. N. Hasegawa, H. Okamoto, M. Kawasumi, M. Kato, A. Tsukigase and A. Usuki, Macromol. Mater. Eng., 280, 76 (2000).

345. N. Hasegawa and A. Usuki, J. Appl. Polym. Sci., 93, 464 (2004).

346. D. Kaempfer, R. Thomann and R. Mülhaupt, Polymer, 43, 2909 (2002).

347. P. Reichert, B. Hoffmann, T. Bock, R. Thomann, R. Mülhaupt and C. Friedrich, Macromol. Rapid Commun., 22, 519 (2001).

348. O. Monticelli, Z. Musina, S. Russo and S. Bals, Mater. Lett., 61, 3446 (2007).

349. E. Manias, A. Touny, L. Wu, K. Strawhecker, B. Lu and T. C. Chung, Chem. Mater., 13, 3516 (2001). 
350. K. Renner, S. Henning, J. Móczó, M. S. Yang, H. J. Choi and B. Pukánszky, Polym. Eng. Sci., 47, 1235 (2007).

351. S. K. Lim, J. W. Kim, I. Chin, Y. K. Kwon and H. J. Choi, Chem. Mater., 14, 1989 (2002)

352. E. Tombácz and M. Szekeres, Appl. Clay Sci., 27, 75 (2004).

353. M. Okamoto, S. Morita, Y. H. Kim, T. Kotaka and H. Tateyama, Polymer, 42, 1201 (2001).

354. R. Wagener and T. J. G. Reisinger, Polymer, 44, 7513 (2003).

355. M. Okamoto, P. H. Nam, P. Maiti, T. Kotaka, N. Hasegawa and A. Usuki, Nano. Lett., 1, 295 (2001).

356. J. Li, C. X. Zhou, G. Wang and D. L. Zhao, J. Appl. Polym. Sci., 89, 3609 (2003).

357. S. Varghese and J. Karger-Kocsis, Polymer, 44, 4921 (2003).

358. N. Moussaif and G. Groeninckx, Polymer, 44, 7899 (2003).

359. W. Lertwilmolnun and B. Vergnes, Polymer, 46, 3462 (2005).

360. Á. Ábrányi, L. Százdi, B. Jr. Pukánszky, J. G. Vancso and B. Pukánszky, Macromol. Rapid Comm., 27, 132 (2006).

361. L. Büki, E. Gönczy, E. Fekete, G. P. Hellmann and B. Pukánszky, Macromol. Symp., 170, 9 (2001).

362. Sz. Molnár, S. Rosenberger, J. Gulyás and B. Pukánszky, J. Macromol. Sci., B38, 721 (1999).

363. E. Fekete, B. Pukánszky and Z. Peredy, Angew. Makromol. Chem., 199, 87 (1992).

364. A. Okada and A. Usuki, Mater. Sci. Eng., C3, 109 (1995).

365. T. X. Liu, Z. H. Liu, K. X. Ma, L. Shen, K. Y. Zeng and C. B. He, Compos. Sci. Technol., 63, 331(2003).

366. J. S. Shelley, P. T. Mather and K. L. DeVries, Polymer, 42, 5849 (2001).

367. T. D. Fornes, P. J. Yoon, D. L. Hunter, H. Keskkula and D. R. Paul, Polymer, 43, 
5915 (2002).

368. T. D. Fornes, P. J. Yoon, H. Keskkula and D. R. Paul, Polymer, 42, 9929 (2001).

369. A. Usuki, M. Kawasumi, Y. Kojima, A. Okada, T. Kurauchi and O. Kamigaito, J. Mater. Res., 8, 1174 (1993).

370. L. Rácz, B. Pukánszky and A. Pozsgay, Prog. Colloid Polym. Sci., 125, 96 (2004).

371. J. C. Santamarina, K. A. Klein, Y. H. Wang and E. Prencke, Can. Geotech. J., 39, 233 (2002).

372. B. K. G. Theng, The chemistry of clay-organic reactions, Hilger, London, (1974).

Table $1 \quad$ Consumption of particulate fillers in Europe in 2007 [6] 


\begin{tabular}{|l|c|}
\hline \multicolumn{1}{|c|}{ Filler } & Amount (ton) \\
\hline \hline Carbon black & $2,000,000$ \\
\hline Natural calcium carbonate and dolomite & $1,500,000$ \\
\hline Aluminium hydroxide & 250,000 \\
\hline Precipitated silica & 225,000 \\
\hline Talc & 200,000 \\
\hline Kaolin and clay & 200,000 \\
\hline Fumed silica & 100,000 \\
\hline Cristobalite, quartz & 100,000 \\
\hline Precipitated calcium carbonate & 75,000 \\
\hline Calcined clay & 50,000 \\
\hline Magnesium hydroxide & 20,000 \\
\hline Wollastonite & 20,000 \\
\hline Wood flour and fiber & 20,000 \\
\hline
\end{tabular}

Table 2 Surface tension of selected polymers and fillers; dispersion $\left(\gamma^{\mathrm{d}}\right)$ and polar $\left(\gamma^{\mathrm{p}}\right)$ 
components

\begin{tabular}{|c|c|c|c|}
\hline \multirow[t]{2}{*}{ Material } & \multicolumn{3}{|c|}{ Surface tension $\left(\mathrm{mJ} / \mathrm{m}^{2}\right)$} \\
\hline & $\gamma^{\mathrm{d}}$ & $\gamma^{\mathrm{p}}$ & $\gamma$ \\
\hline $\mathrm{PP}^{\mathrm{a}}$ & 32.5 & 0.9 & 33.4 \\
\hline PMMA $^{\mathrm{a}}$ & 34.3 & 5.8 & 40.1 \\
\hline $\mathrm{CaCO}_{3}{ }^{\mathrm{b}}$ & 54.5 & 153.4 & 207.9 \\
\hline $\operatorname{talc}^{\mathrm{c}}$ & 49.3 & 90.1 & 139.4 \\
\hline $\mathrm{SiO}_{2}{ }^{\mathrm{C}}$ & 94.7 & 163.0 & 257.7 \\
\hline
\end{tabular}

${ }^{\mathrm{a}}$ contact angle, ${ }^{\mathrm{b}} \mathrm{IGC},{ }^{\mathrm{c}}$ gravimetric measurement

Table 3 Interphase thickness in particulate filled polymers determined by different 
techniques

\begin{tabular}{|c|c|c|c|c|}
\hline $\begin{array}{c}\text { Matrix } \\
\text { polymer }\end{array}$ & Filler & $\begin{array}{c}\text { Method of } \\
\text { determination }\end{array}$ & Thickness $(\mu \mathrm{m})$ & Reference \\
\hline \hline $\mathrm{HDPE}$ & $\mathrm{SiO}_{2}$ & extraction & 0.0036 & 201 \\
\hline $\mathrm{HDPE}$ & $\mathrm{SiO}_{2}$ & $n$ & 0.0036 & 199 \\
\hline PP & $\mathrm{SiO}_{2}$ & & 0.0041 & 199 \\
\hline PP & graphite & model calc. & 0.001 & 200 \\
\hline PS & mica & dyn. mech. meas. & 0.06 & 202 \\
\hline PMMA & glass & dyn. mech. meas. & 1.4 & 202 \\
\hline PP & $\mathrm{CaCO}_{3}$ & Young's modulus & 0.012 & 208 \\
\hline PP & $\mathrm{CaCO}_{3}$ & tensile strength & 0.15 & 208 \\
\hline PP & $\mathrm{CaCO}_{3}$ & tensile yield stress & 0.16 & 208 \\
\hline PP & $\mathrm{CaCO}_{3}$ & tensile yield stress & 0.12 & 207 \\
\hline LDPE & $\mathrm{CaCO}_{3}$ & tensile yield stress & 0.11 & 207 \\
\hline PMMA & $\mathrm{CaCO}_{3}$ & tensile yield stress & 0.18 & 207 \\
\hline PVC & $\mathrm{CaCO}_{3}$ & tensile yield stress & 0.23 & 207 \\
\hline
\end{tabular}

\section{CAPTIONS}

Fig. 1 Effect of matrix properties on the tensile yield stress of particulate filled composites. Particle size of $\mathrm{CaCO}_{3}, \mathrm{R}=1.8 \mu \mathrm{m}$. 
Fig. 2 Particle size distributions of fillers showing a tendency for agglomeration. Dependence of distribution on the method of determination.

Fig. 3 Effect of filler anisotropy on the flexural modulus of PP composites [9 long].

Fig. 4 Correlation between the heat of crystallization and yield stress of $\mathrm{PP} / \mathrm{CaCO}_{3}$ composites [36 KeKo 2].

Fig. 5 Strength of $\mathrm{PP} / \mathrm{CaCO}_{3}$ composites plotted as a function of the specific surface area of the filler. Effect of aggregation.

Fig. 6 Initiation and propagation of a crack through an aggregate of $\mathrm{CaCO}_{3}$ particles in a PP composite.

Fig. 7 Effect of fiber orientation (alignment to external stress) on the strength of short glass fiber reinforced PP composites [162 long].

Fig. 8 Effect of interfacial adhesion on the tensile yield stress of $\mathrm{PP} / \mathrm{CaCO}_{3}$ composites; filler: $\mathrm{CaCO}_{3}, \varphi_{\mathrm{f}}=0.1, \mathrm{R}=0.9 \mu \mathrm{m}$.

Fig. 9 Effect of interfacial interactions on the thickness of the interlayer formed spontaneously in polymer/ $\mathrm{CaCO}_{3}$ composites.

Fig. 10 Effect of the size of the interfacial area on the yield stress of $\mathrm{PP} / \mathrm{CaCO}_{3}$ composites.

Fig. 11 Wettability of $\mathrm{CaCO}_{3}$ by PP and its dependence on the surface coverage of the filler with stearic acid.

Fig. 12 Dissolution curve used for the determination of surfactant adsorption on a filler. $\mathrm{CaCO}_{3} /$ stearic acid.

Fig. 13 Effect of the chemical structure of silane coupling agents on their adsorption on the surface of $\mathrm{a} \mathrm{CaCO}_{3}$ filler. Particle size $1.25 \mu \mathrm{m}$.

Fig. 14 Effect of the interdiffusion of the functionalized polymer with the matrix on the mechanical properties of PP/cellulose composites. 
Fig. 15 Dependence of debonding stress derived from volume strain measurements on the stiffness of the matrix (see Eq. 11).

Fig. 16 Acoustic activity expressed as the cumulative number of acoustic events for neat PP (---------) and for a composite containing $20 \mathrm{wt} \%$ wood without MAPP (poor adhesion) ( $\longrightarrow$ ).

Fig. 17 SEM micrograph showing the fracture of a wood particle during the deformation of PP/wood composites. Good adhesion of the components was achieved by the use of functionalized MAPP (Licomont AR 504).

Fig. $18 \quad \sigma$ vs. $\sigma_{\mathrm{AE}}-$ PP, PLA általános

Fig. 19 Relative tensile yield stress of the $\mathrm{PP} / \mathrm{CaCO}_{3}$ composites presented in Fig. 11 plotted against composition in the linear representation of Eq. 19. Symbols are the same as in Fig. 11.

Fig. 20 Comparison of the effect of carbon black (CB), multiwalled (MWCNT) and single walled carbon nanotubes (SWCNT) on the conductivity of polycarbonate composites.

Móczó, Fig. 1 


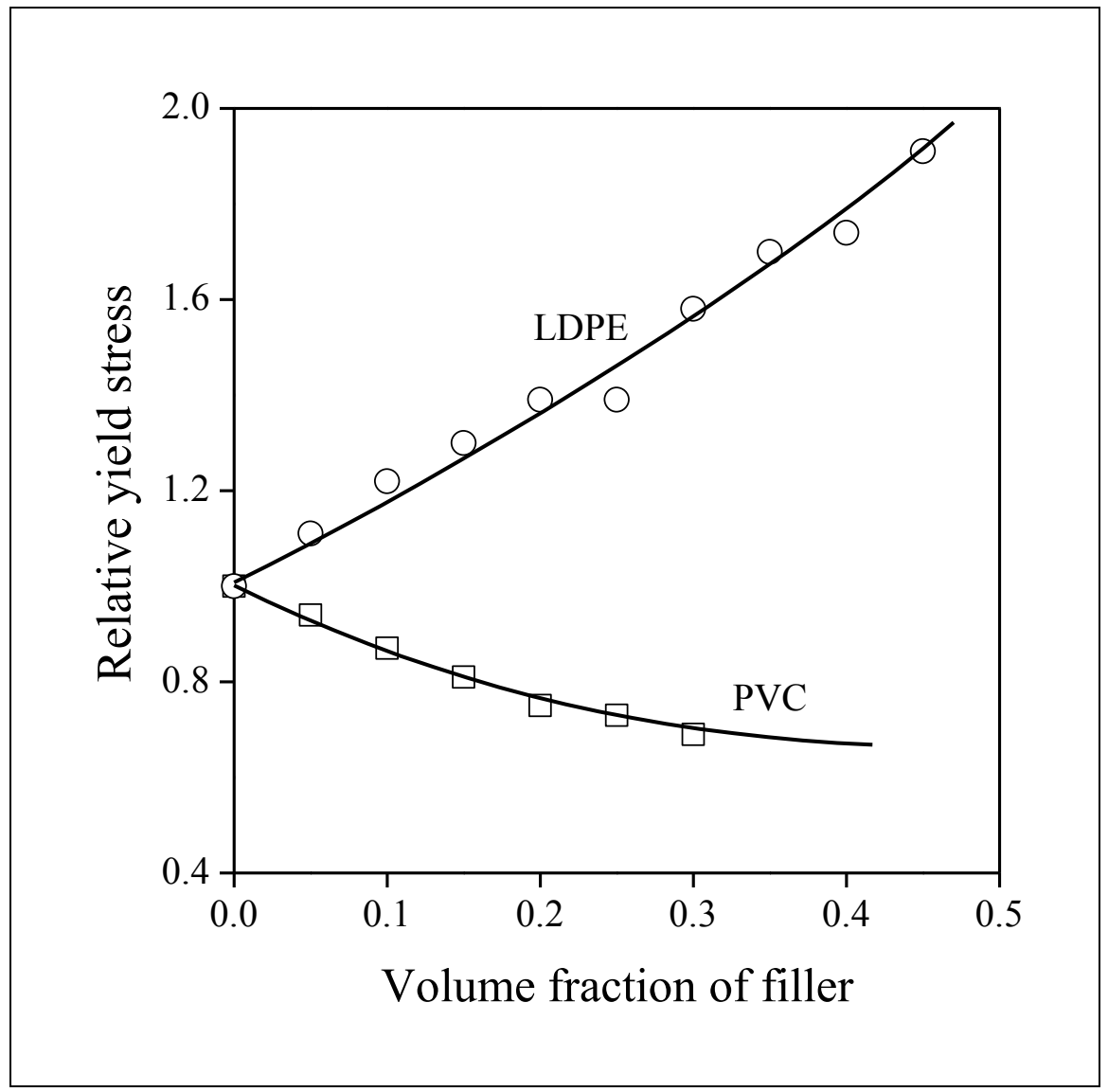

Móczó, Fig. 2 


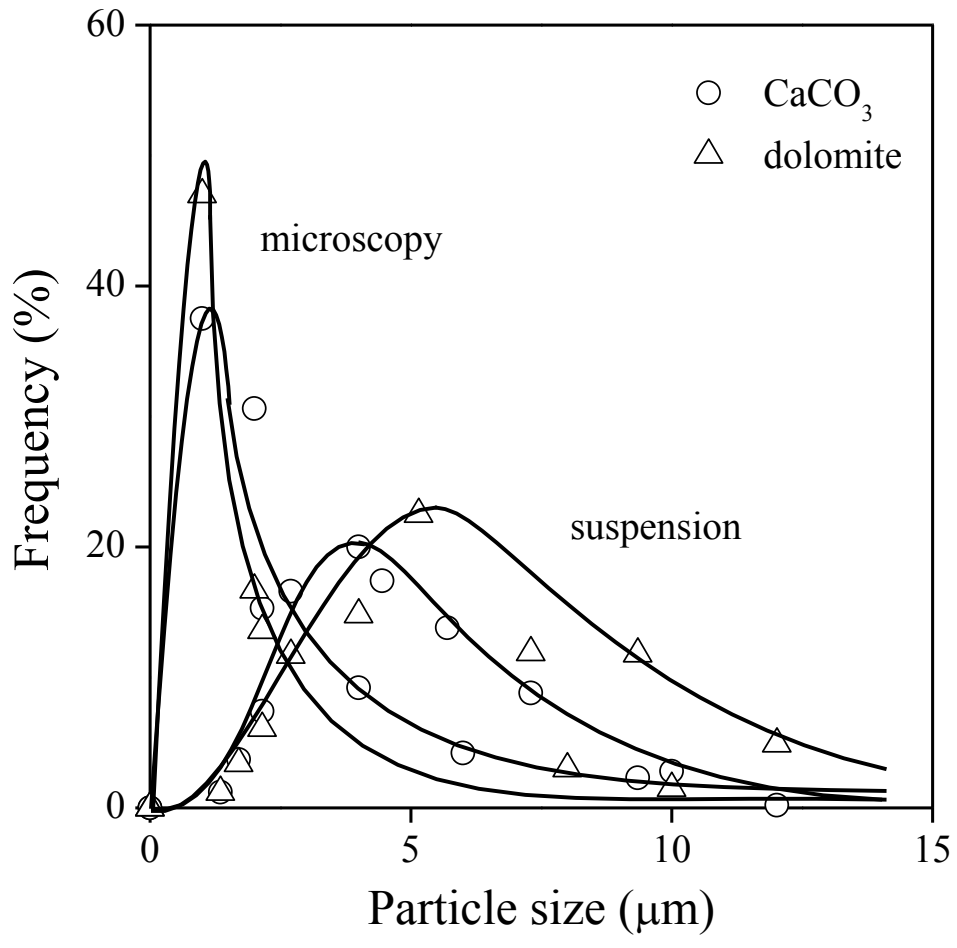

Móczó, Fig. 3 


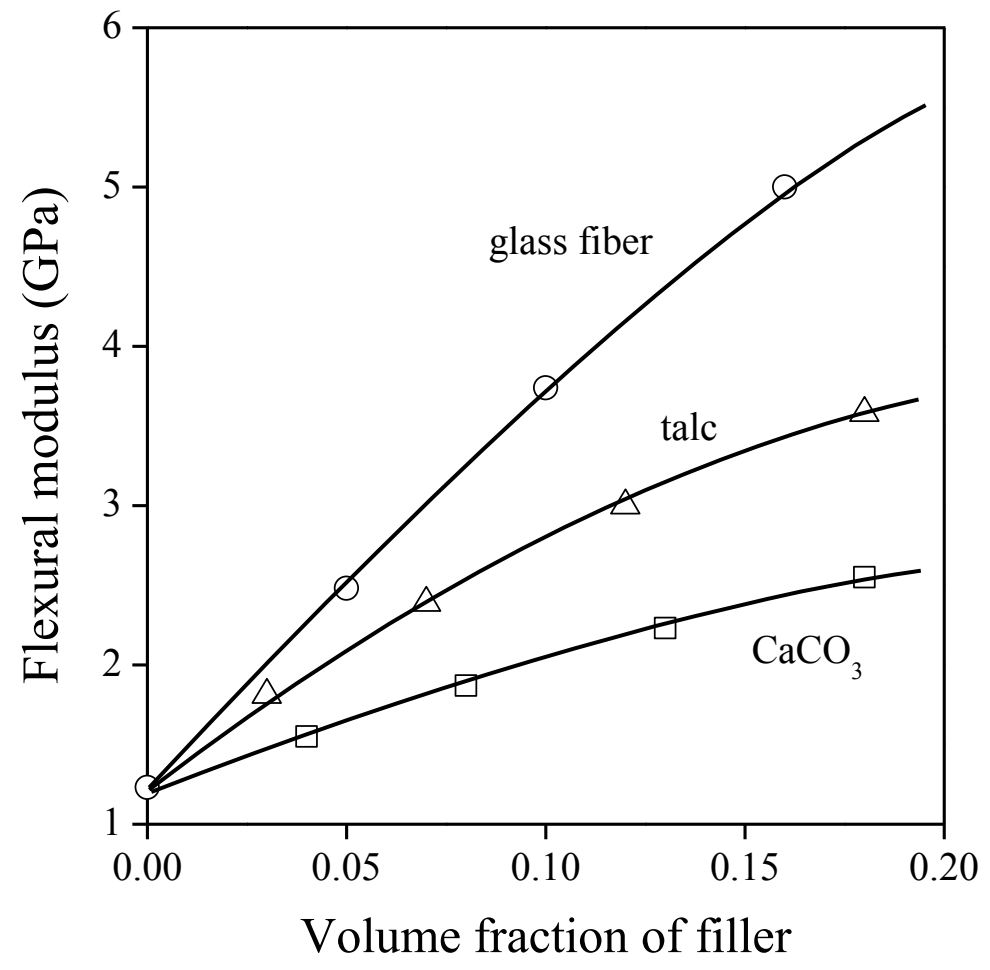

Móczó, Fig. 4 


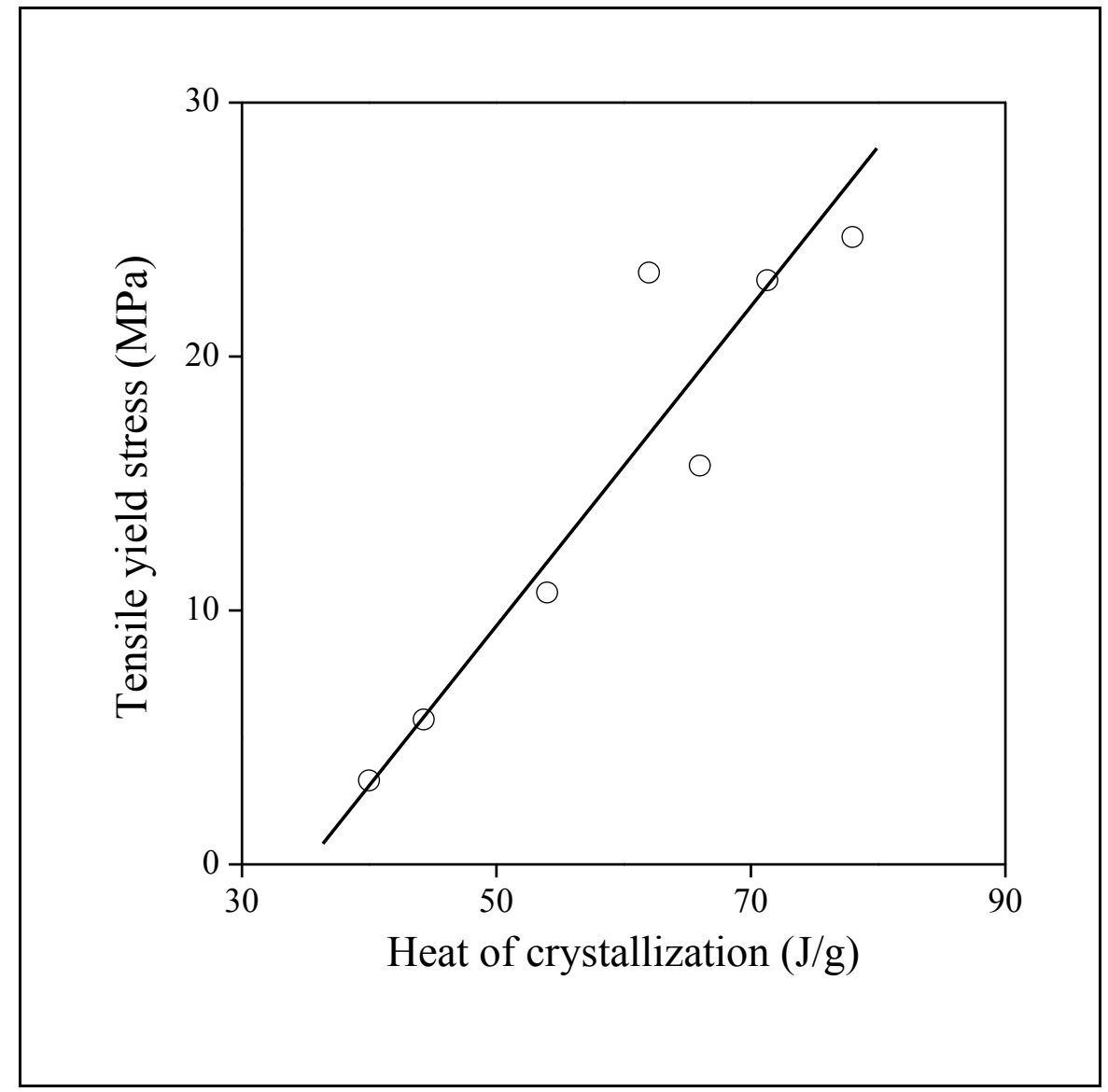

Móczó, Fig. 5 


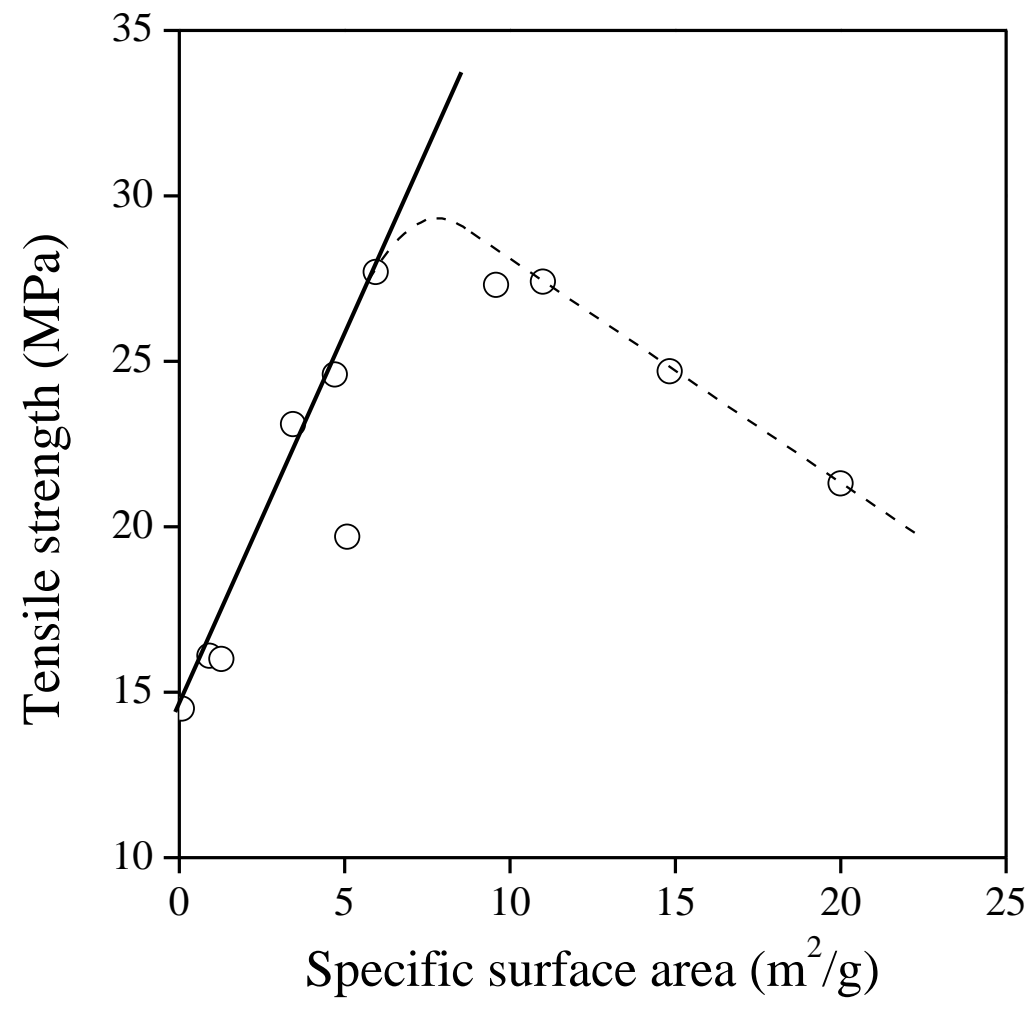

Móczó, Fig. 6 


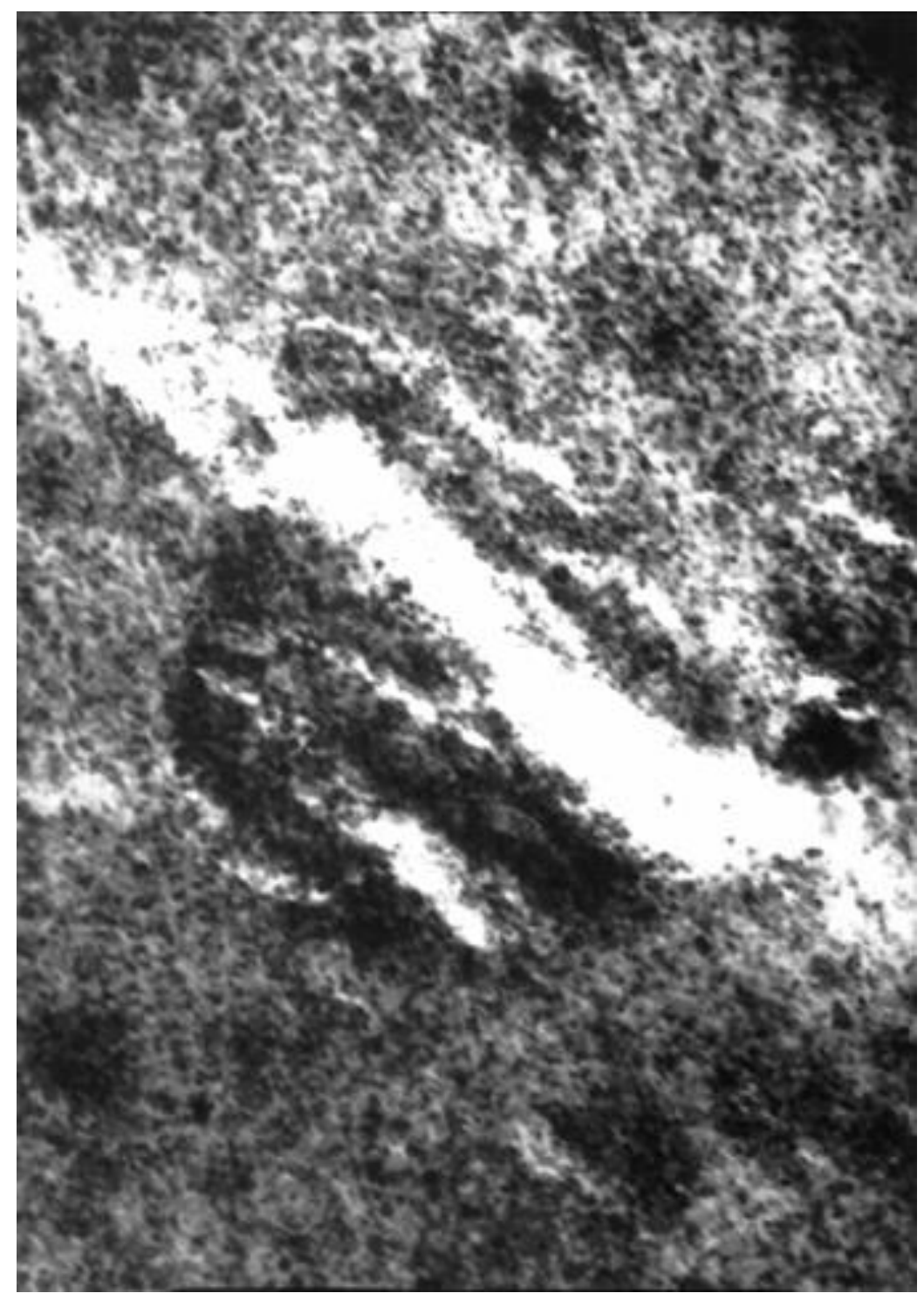

Móczó, Fig. 7 


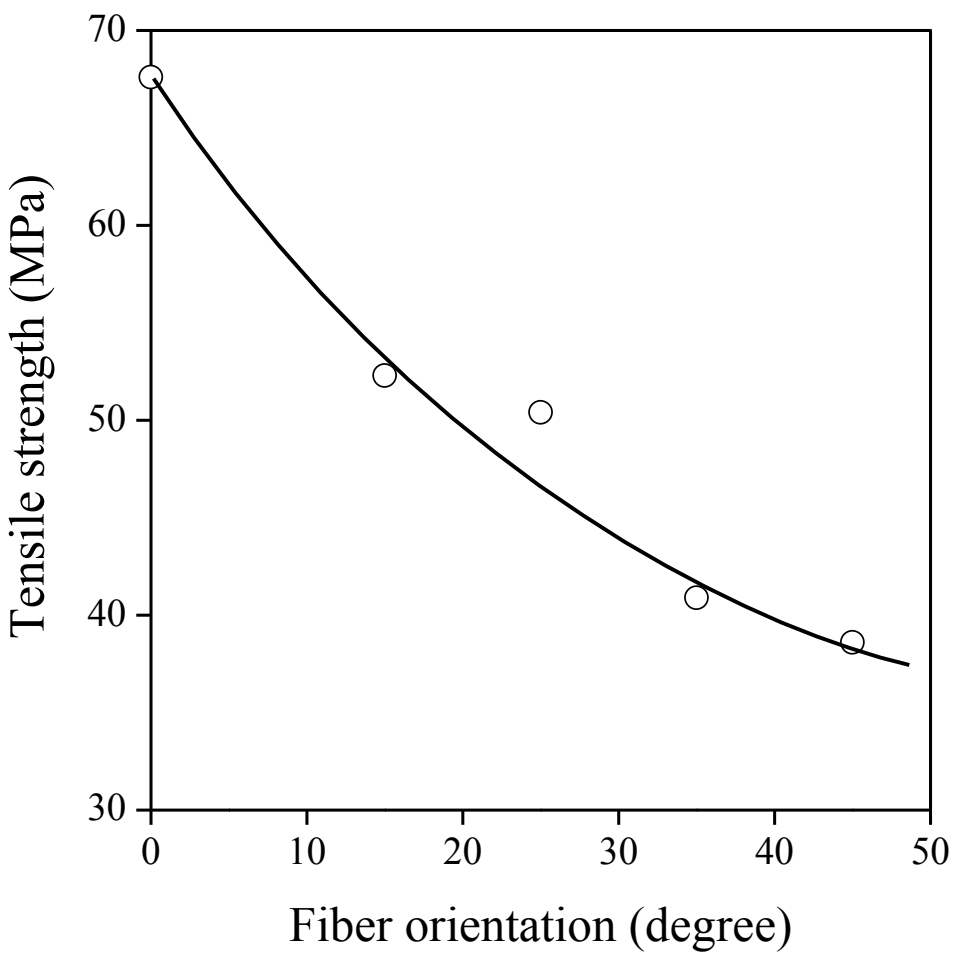

Móczó, Fig. 8 


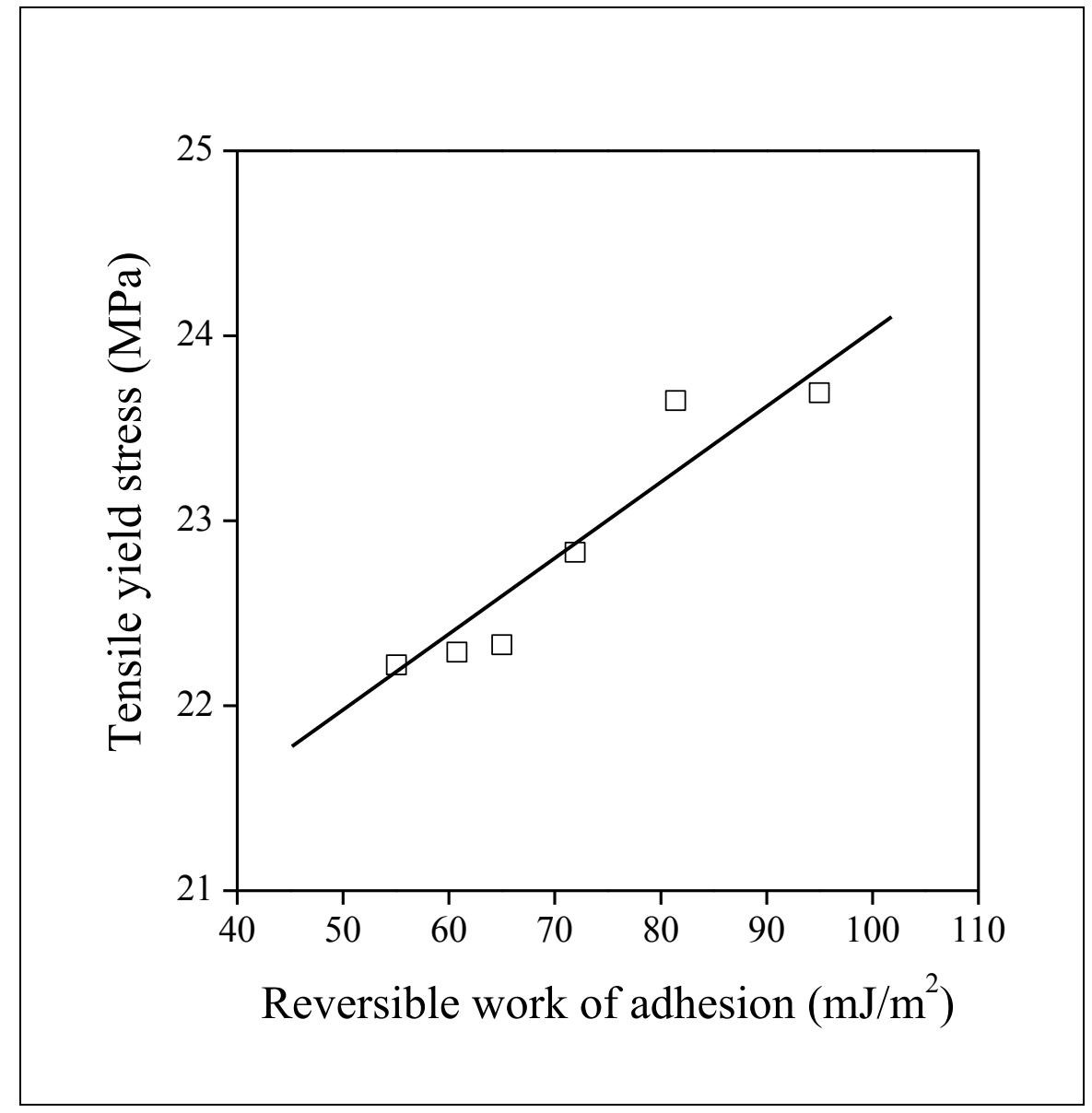

Móczó, Fig. 9 


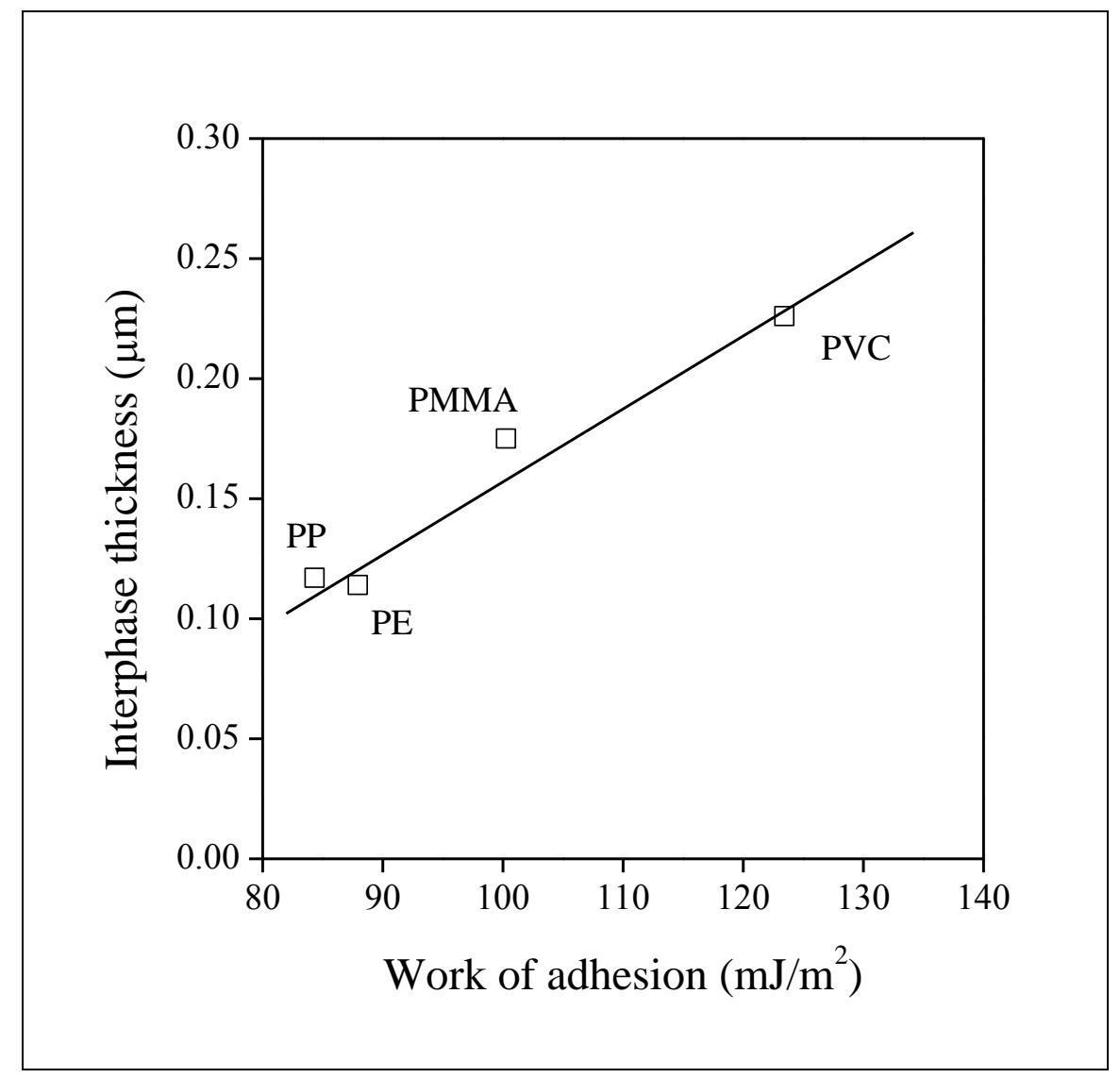

Móczó, Fig. 10 


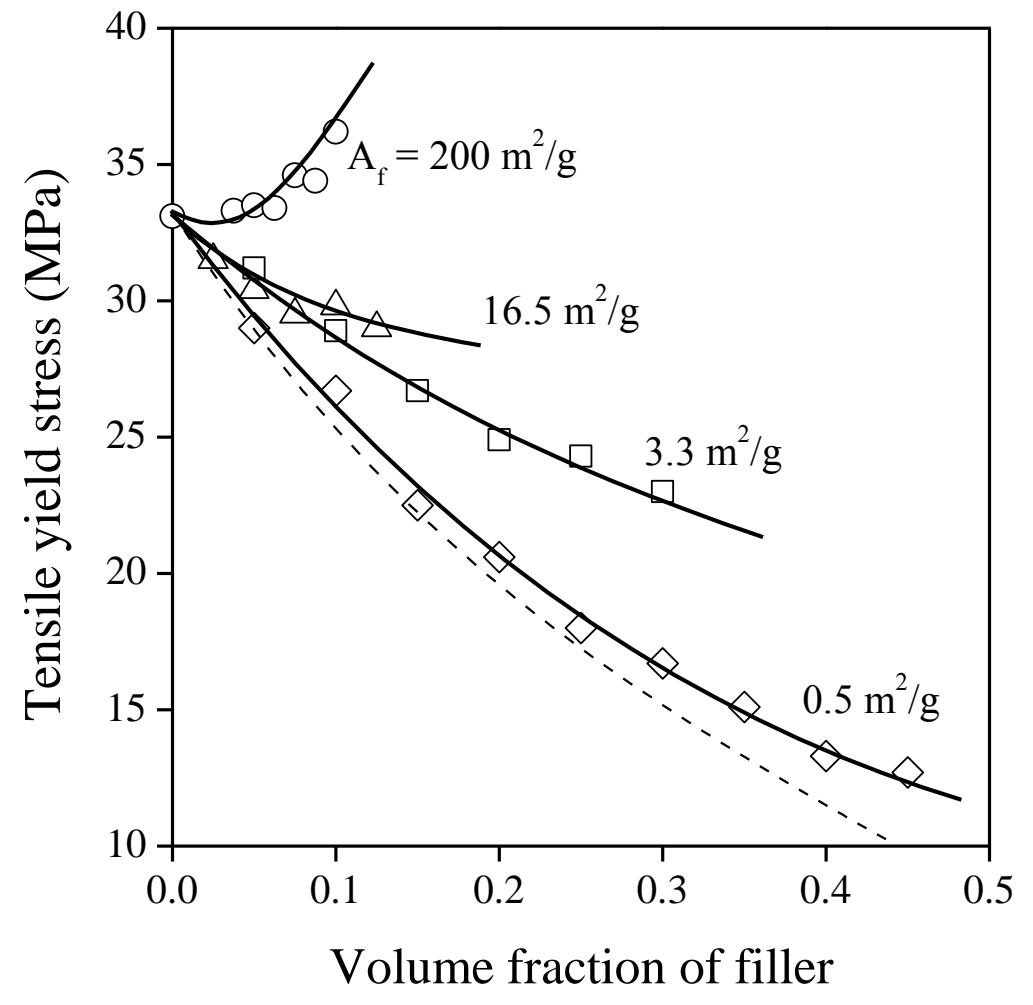

Móczó, Fig. 11 


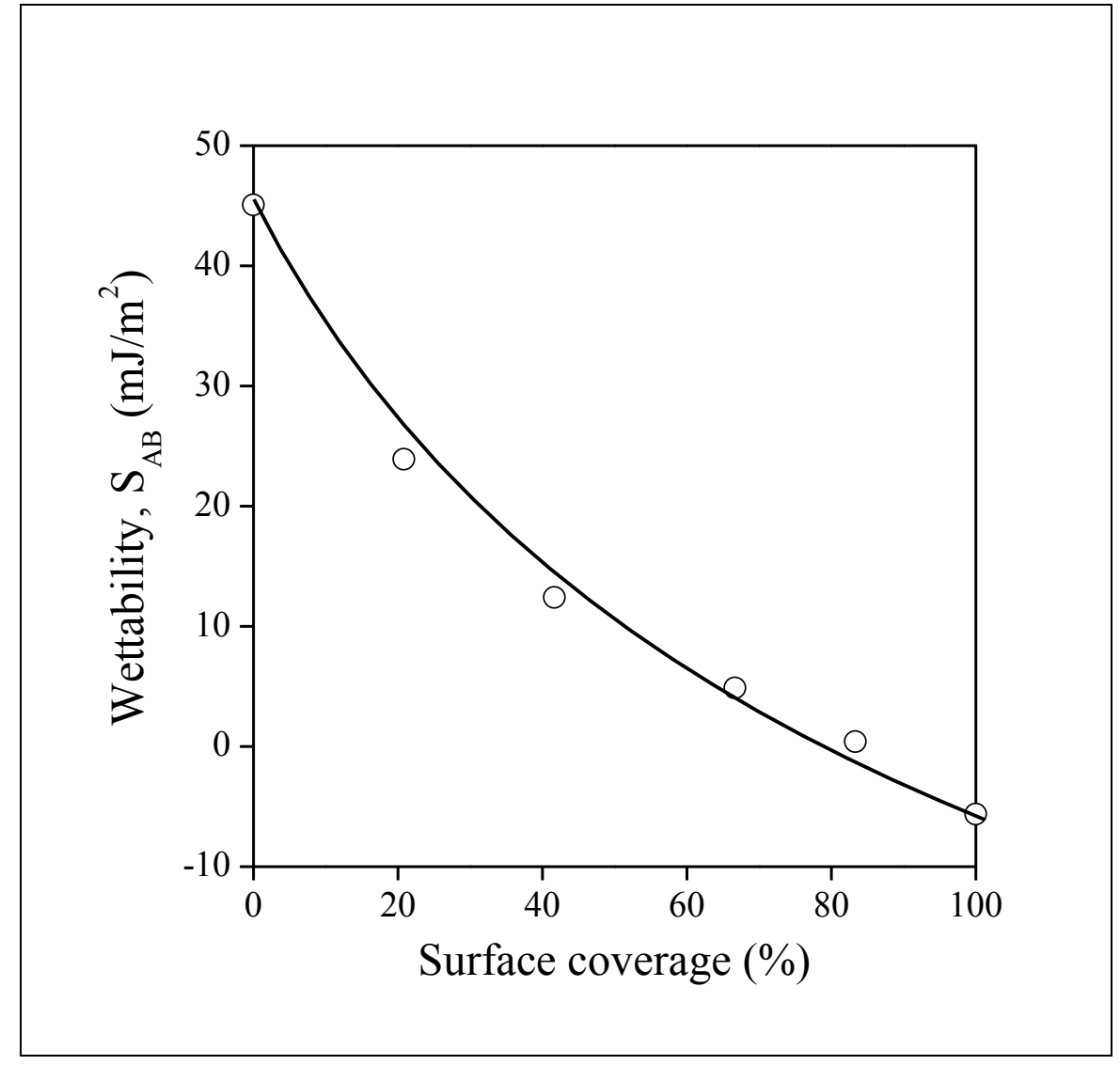

Móczó, Fig. 12 


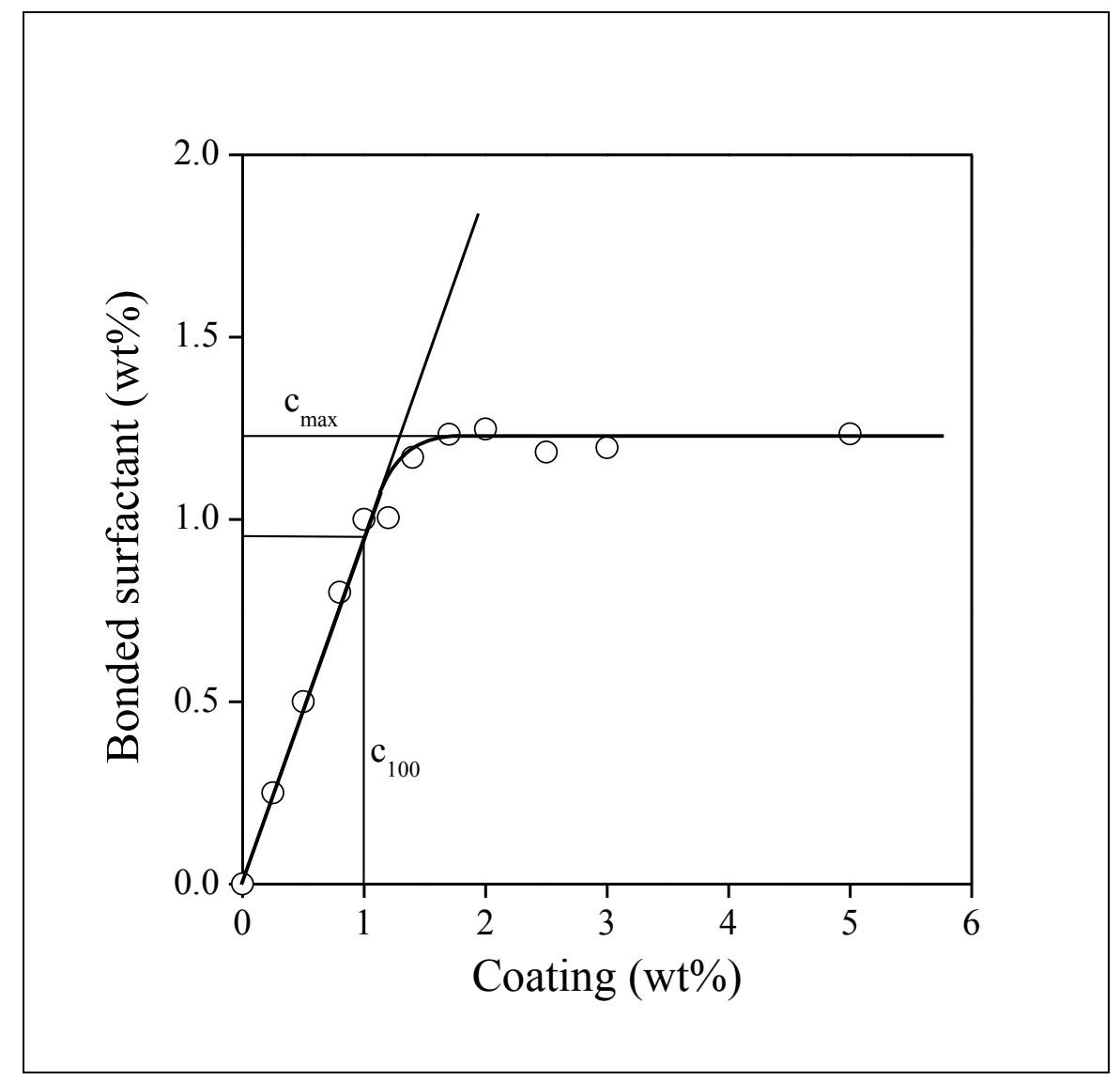

Móczó, Fig. 13 


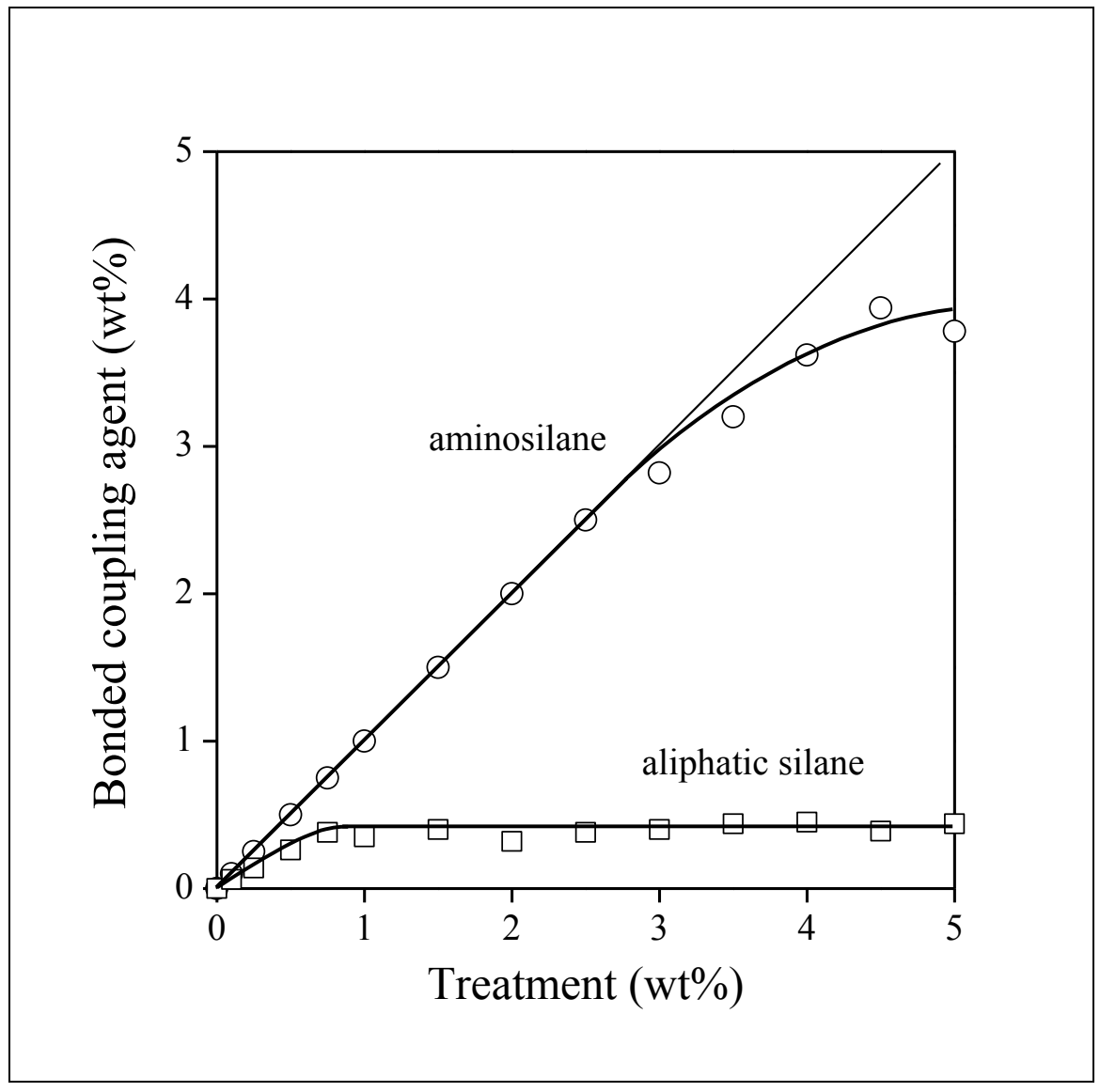

Móczó, Fig. 14 


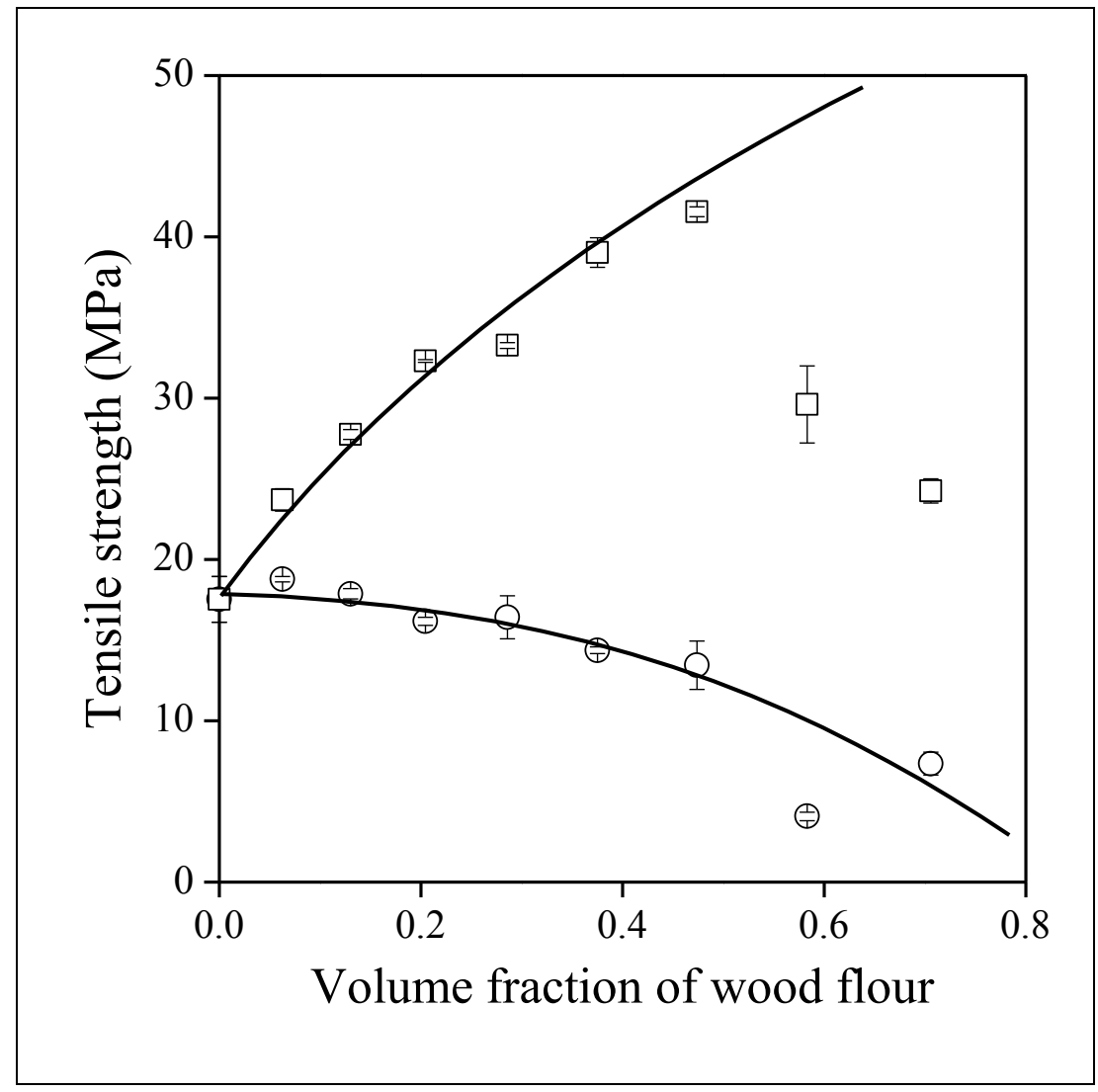

Móczó, Fig. 15 


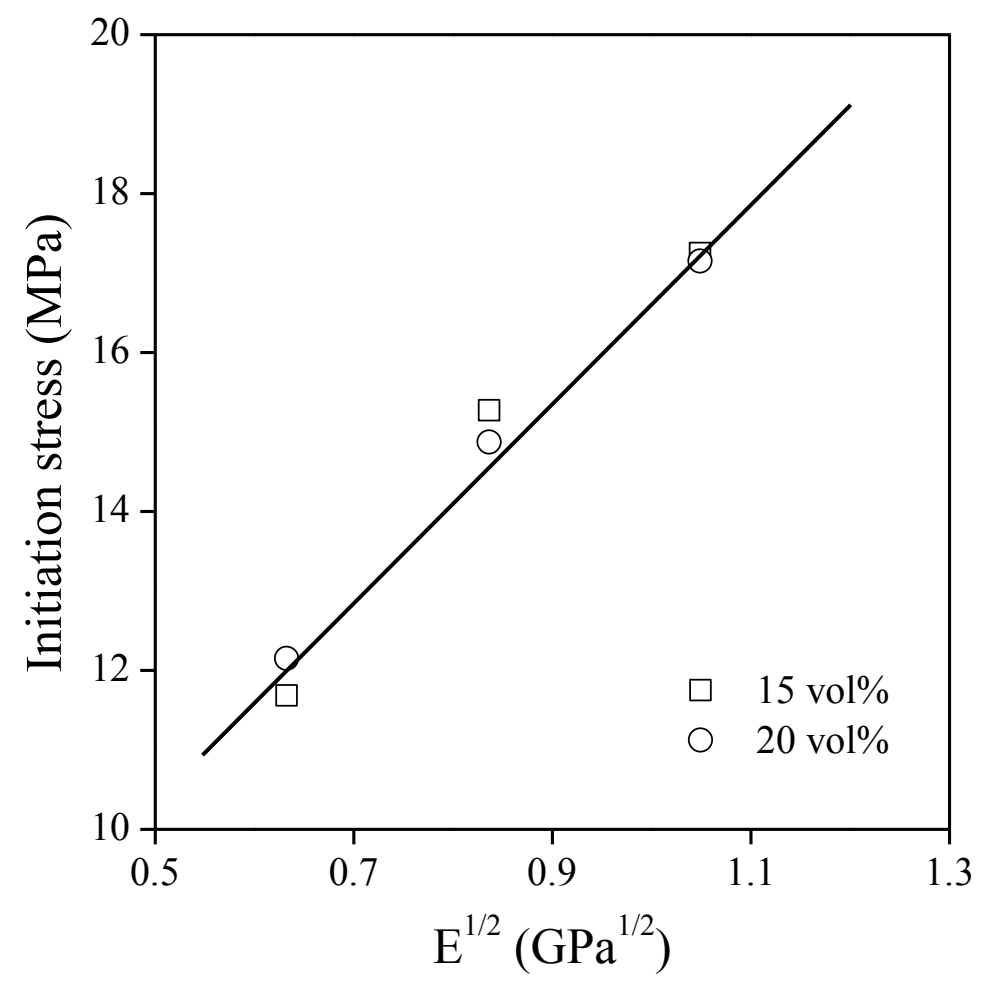

Móczó, Fig. 16 


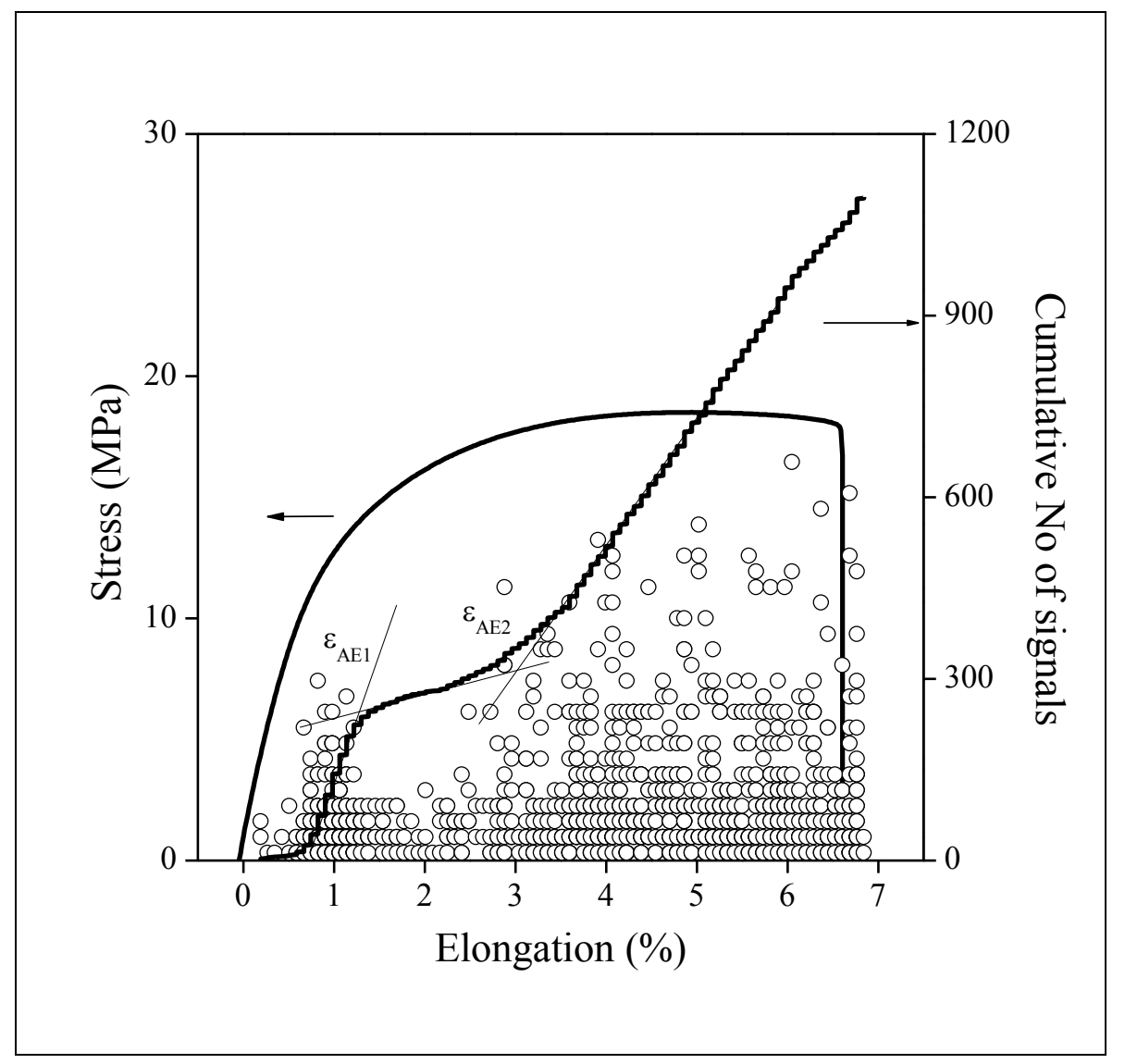

Móczó, Fig. 17 


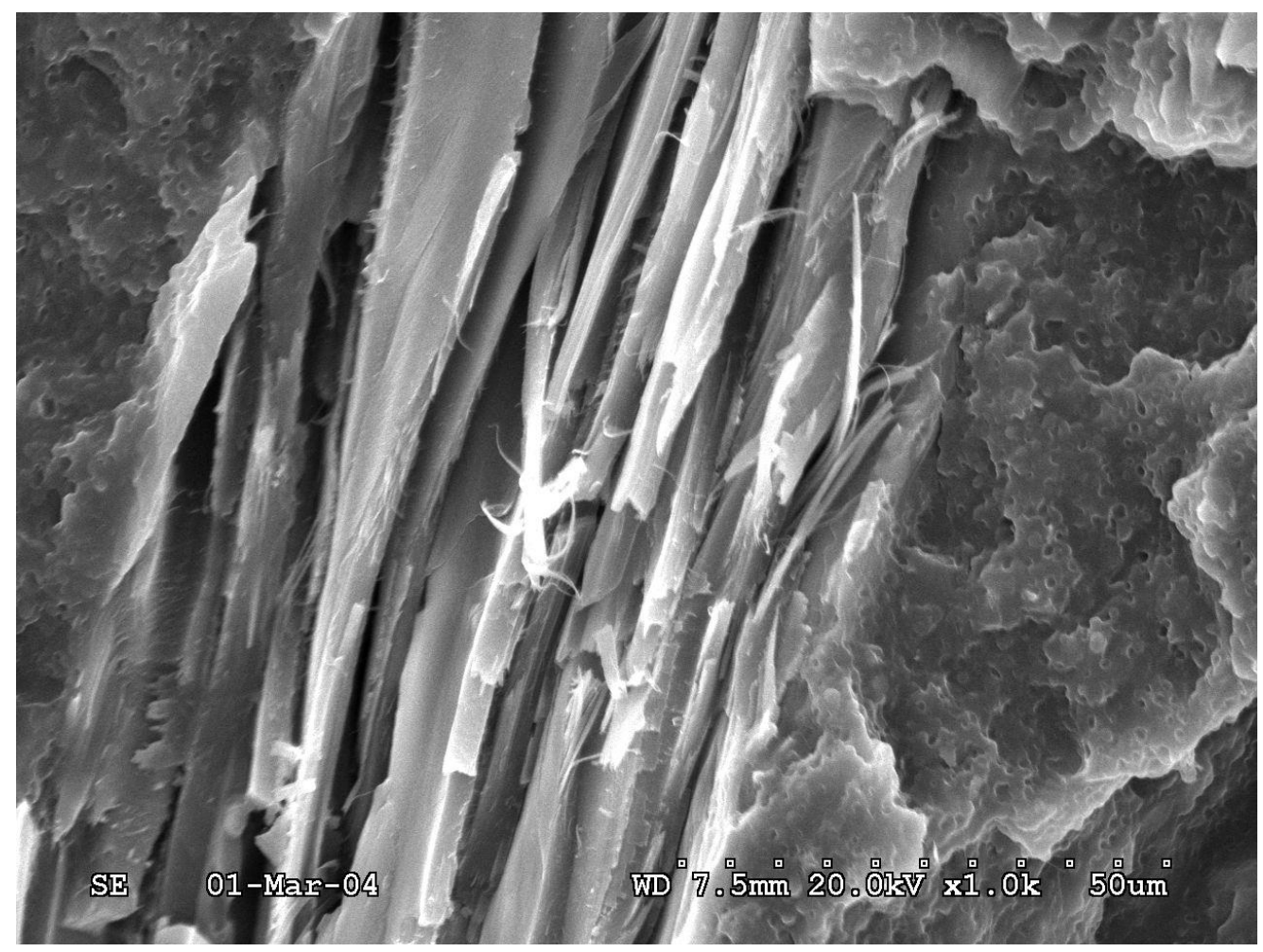

Móczó, Fig. 18 


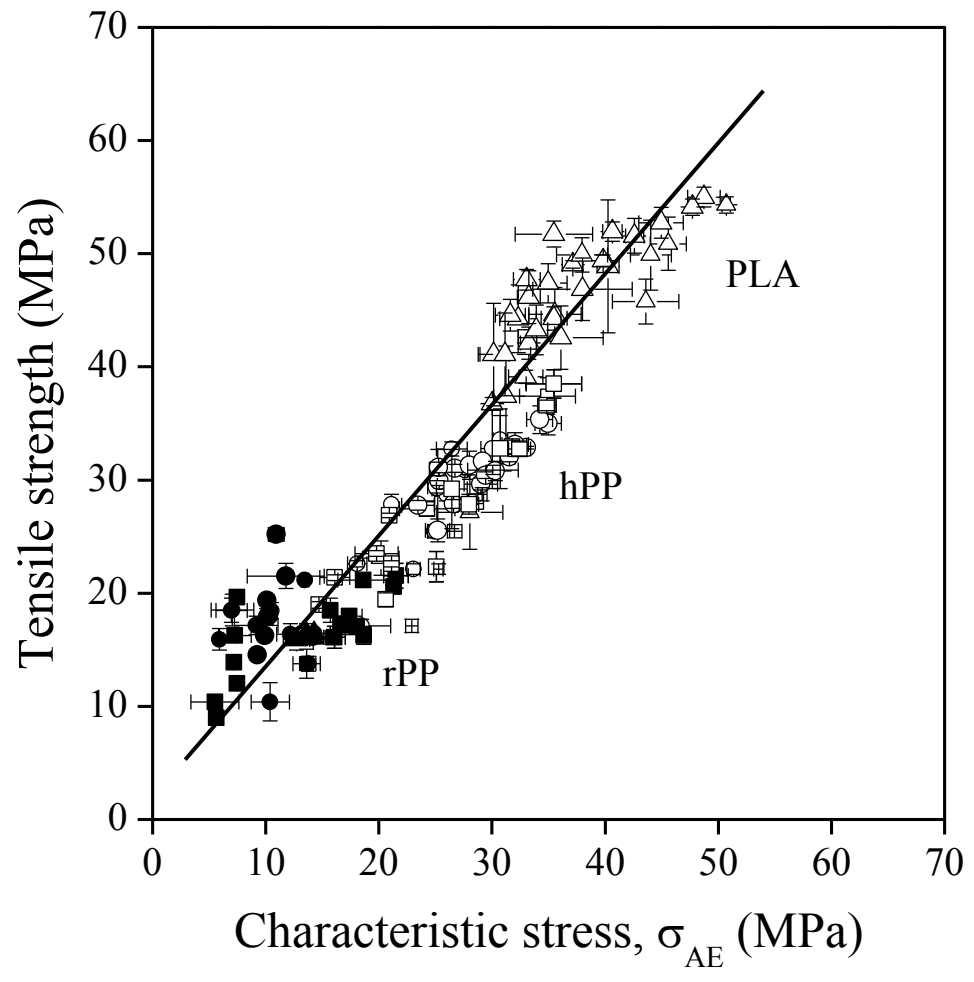

Móczó, Fig. 19 


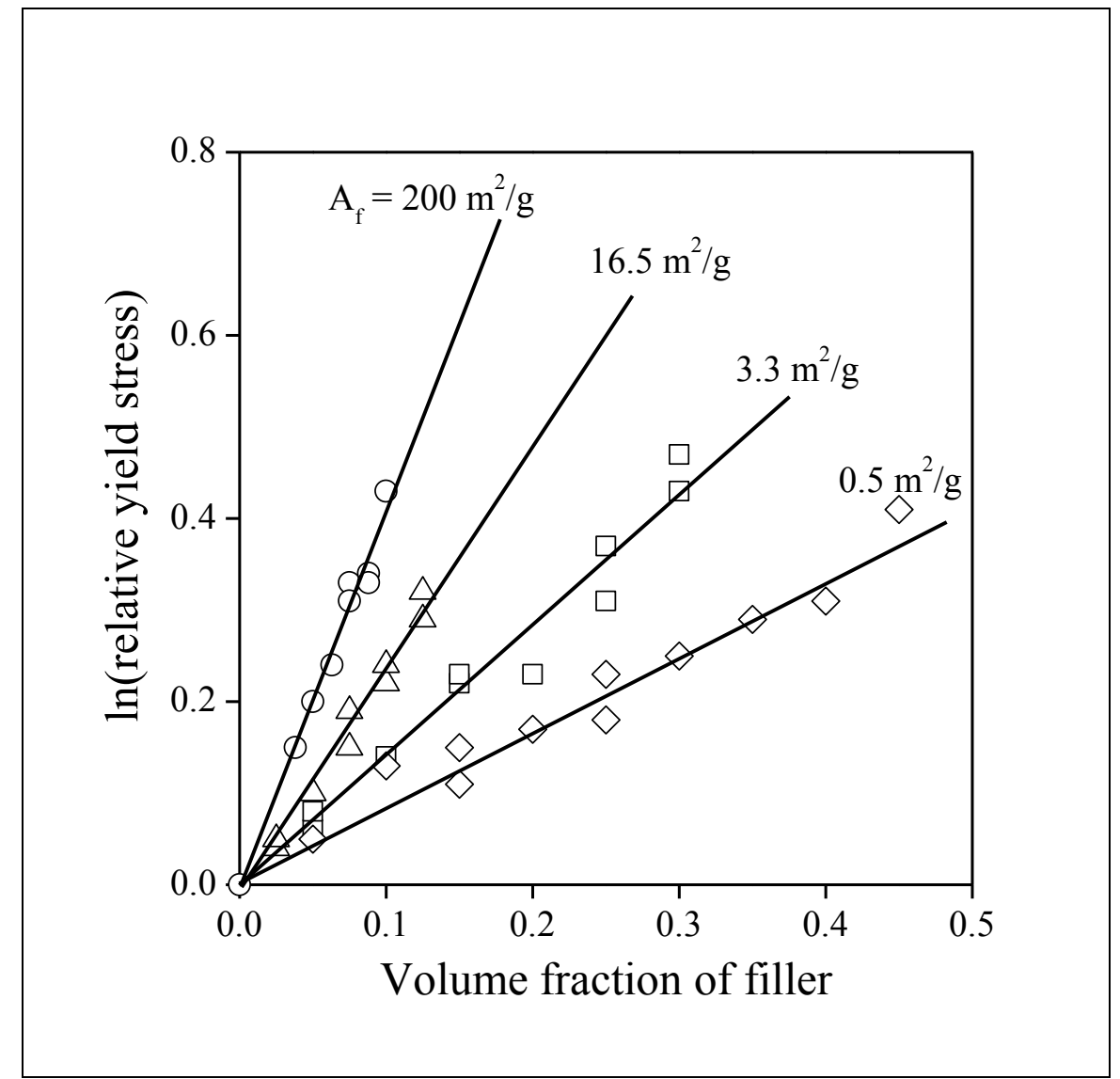

Móczó, Fig. 20 


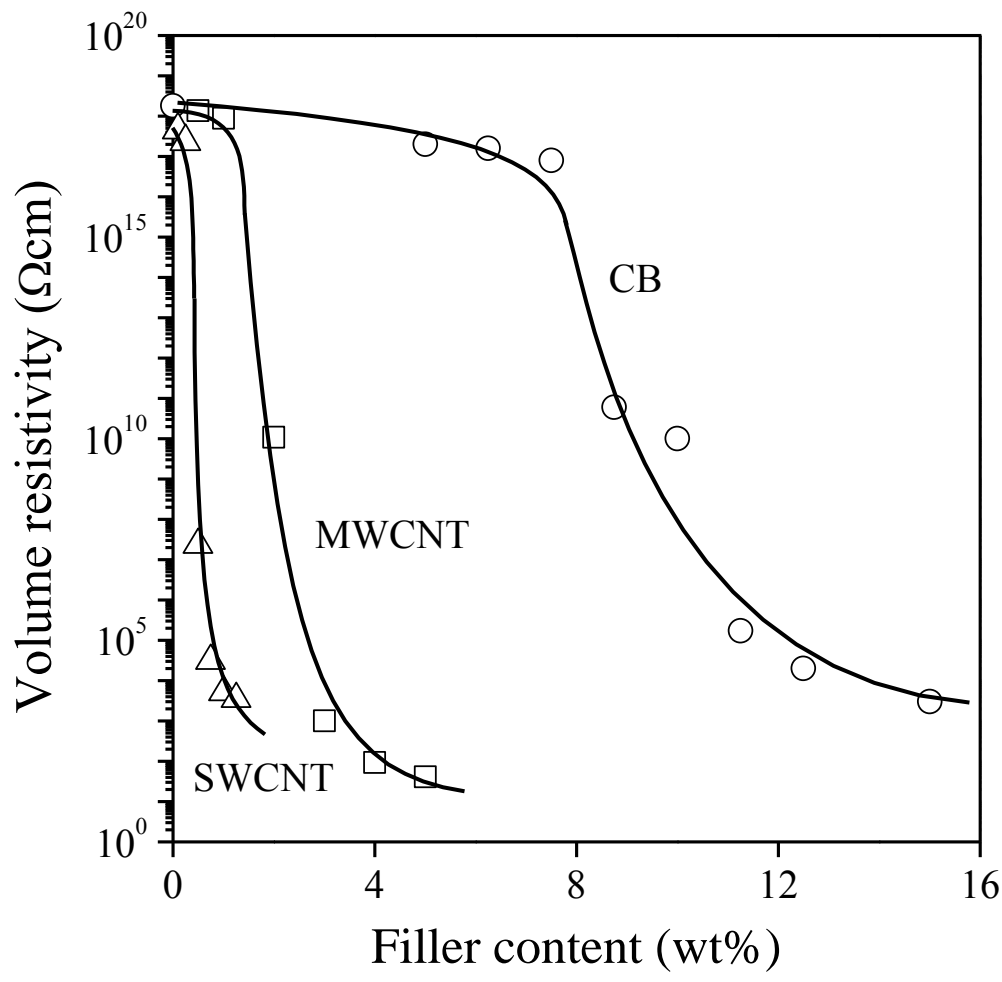

